\title{
Hemodynamics and Mechanobiology of Aortic Valve Inflammation and Calcification
}

\author{
Kartik Balachandran, ${ }^{1}$ Philippe Sucosky, ${ }^{2}$ and Ajit P. Yoganathan ${ }^{3}$ \\ ${ }^{1}$ Wyss Institute for Biologically Inspired Engineering, School of Engineering and Applied Sciences, Harvard University, \\ Cambridge, MA 02138, USA \\ ${ }^{2}$ Department of Aerospace and Mechanical Engineering, University of Notre Dame, 143 Multidisciplinary Research Building, \\ Notre Dame, IN 46556-5637, USA \\ ${ }^{3}$ The Wallace H. Coulter Department of Biomedical Engineering, Georgia Institute of Technology, 313 Ferst Drive, Suite 1121, \\ Atlanta, GA 30332-0535, USA
}

Correspondence should be addressed to Ajit P. Yoganathan, ajit.yoganathan@bme.gatech.edu

Received 18 March 2011; Accepted 29 April 2011

Academic Editor: Elena Aikawa

Copyright ( $\odot 2011$ Kartik Balachandran et al. This is an open access article distributed under the Creative Commons Attribution License, which permits unrestricted use, distribution, and reproduction in any medium, provided the original work is properly cited.

Cardiac valves function in a mechanically complex environment, opening and closing close to a billion times during the average human lifetime, experiencing transvalvular pressures and pulsatile and oscillatory shear stresses, as well as bending and axial stress. Although valves were originally thought to be passive pieces of tissue, recent evidence points to an intimate interplay between the hemodynamic environment and biological response of the valve. Several decades of study have been devoted to understanding these varied mechanical stimuli and how they might induce valve pathology. Here, we review efforts taken in understanding the valvular response to its mechanical milieu and key insights gained from in vitro and ex vivo whole-tissue studies in the mechanobiology of aortic valve remodeling, inflammation, and calcification.

\section{Introduction}

Cardiac valves are dynamic, sophisticated structures which interact closely with the surrounding hemodynamic environment. The aortic valve located between the left ventricle and the aorta and the pulmonary valve positioned between the right ventricle and the pulmonary artery are designated as semilunar valves and prevent the backflow of blood from the respective outflow tracts into the ventricles. The atrioventricular valves that ensure the blood to flow from the atria to the ventricles consist of the mitral valve located between the left atrium and left ventricle and the tricuspid valve lying between the right atrium and the right ventricle. Although these four valves present different anatomies and different opening/closing characteristics, they allow the unidirectional flow of blood while maximizing flow rate and minimizing resistance to flow. Although valves were originally thought to be passively moving due to blood flow, it is now acknowledged that the mechanisms ensuring the proper structure and function of the heart valves are essentially controlled by the interaction between the valve, its cells, and the surrounding hemodynamic or mechanical environment. Understanding the effect of the mechanical environment on heart valve biology, that is, its mechanobiology, is therefore critical to better understand normal valve function and disease progression. This paper presents a detailed review of the hemodynamics and mechanobiology of the cardiac valve as it relates to valve pathology, with an emphasis on the aortic valve. The paper is divided into two main sections. The first section summarizes the hemodynamic forces experienced by normal and diseased semilunar valves and closes with a detailed description of the hemodynamic forces experienced by the aortic valve. The second section reviews results from recent in vitro and ex vivo studies on the effects of these hemodynamic forces on aortic valve biology and disease. This paper therefore provides a comprehensive description of the hemodynamics and mechanobiology of the valve in both normal and pathologic conditions, focusing primarily on the aortic valve. 


\section{Organ-Level Semilunar Heart Valve Hemodynamics}

A study of valve mechanobiology will be incomplete without first analyzing the mechanical and hemodynamic milieu of the valve. The purpose of this section therefore is twofold: (I) to qualitatively and quantitatively outline, as best possible, the complex mechanical environment of the valve (Figure 1) and (II) to provide an overall sense of the changes in mechanics that occur due to valve disease. Table 1 consolidates the relevant mechanical benchmarks in terms of practical parameters that can be simulated experimentally.

2.1. Normal Valve Hemodynamics. The aortic valve opens during systole when the ventricle is contracting and then closes during diastole as the ventricle relaxes (Figure 1). In healthy individuals, blood flows through the aortic valve accelerating to a peak value of $1.35 \pm 0.35 \mathrm{~m} / \mathrm{s}$ [1]. The valve closes near the end of the deceleration phase of systole with very little reverse flow through the valve. The adverse axial pressure difference causes the low inertia flow in the developing boundary layer along the aortic wall to decelerate then to reverse direction resulting in vortices in the sinuses behind the aortic valve leaflets [2]. This action forces the belly of the leaflets away from the aortic wall and toward the closed position. When this force is coupled with the vortices that push the leaflet tips toward the closed position, a very efficient and fast closure is obtained. In vitro studies have shown that the axial pressure difference alone is sufficient to close the valve [2]. Thus, without the vortices in the sinuses, the valve still closes, but its closure is not as efficient.

The velocity profile at the level of the aortic valve annulus is relatively flat. However there is a slight skew towards the septal wall (less than $10 \%$ off the center line) caused by the orientation of the aortic valve relative to the long axis of the left ventricle [9]. The flow patterns just downstream of the aortic valve (in the outflow tract) are of particular interest because of their complexity and relationship to arterial disease. Highly skewed velocity profiles and corresponding helical flow patterns have been observed in the human aortic arch using magnetic resonance phase velocity mapping [9]. In vitro flow quantification experiments (via laser Doppler anemometry) have shown that these flow patterns are dependent on the valve geometry and thus can be used to evaluate function and fitness of the heart valve [10].

2.2. Diseased Valve Hemodynamics. Aortic valve pathology, long thought to be due to passive degenerative valve disease caused by increasing longevity coupled with rheumatic and infective endocarditis [11], is now acknowledged to result from active disease processes such as inflammation and modulation of cell phenotype [12-15]. Current surgical interventions include valve repair or replacement depending on the diagnosis. Tremendous progress has been achieved during the last century on the development and improvement of prosthetic valves, but, to date, there is no ideal replacement valve available. Because knowledge of the hemodynamics could be invaluable in the treatment of such pathologies, studies have been done on the characterization of the fluid environment in the vicinity of diseased semilunar valves.

Aortic valve stenosis is a condition characterized by the incomplete opening of the valve. The partial opening of the valve produces an obstruction that limits the forward blood flow from the left ventricle to the aorta. Yoganathan [6] carried out some flow measurements on bioprosthetic valves mimicking different degrees of aortic stenosis in vitro. Under physiologic conditions (heart rate of 70 beats per min, systolic duration of $300 \mathrm{~ms}$, and mean aortic pressure of $90-100 \mathrm{mmHg}$ ), flow visualization demonstrated that the fluid exits from the stenotic valve as an asymmetric, angulated jet. As the degree of stenosis increased, the jet diameter at the base of the aorta decreases and the flow field becomes more disturbed and chaotic (Figure 2). In addition, flow measurements showed that as compared with the evenly distributed flow field obtained at peak systole in the normal aortic valve (maximum axial velocity of $1.20 \mathrm{~m} / \mathrm{s}$ ), the stenotic valve is characterized by a jet-type flow field (maximum axial velocity of $7 \mathrm{~m} / \mathrm{s}$ ) with regions of separation located around the jet and highly turbulent shear layers (maximum rms axial velocity of $2.0 \mathrm{~m} / \mathrm{s}$ ) (Figure 2). The elevated levels of turbulence measured downstream of the stenotic valves are high enough to cause damage to the blood elements (red blood cells and platelets) and the endothelial cells lining the wall of the ascending aorta.

\section{Mechanical Forces Experienced by the Aortic Valve}

3.1. Pressure. In vivo, the pressure on the leaflet varies from systole to diastole, changing the stress and, consequently, the length of the leaflets. Under normal physiological conditions, the closed valve supports a transvalvular pressure of 80 $120 \mathrm{mmHg}$ acting perpendicular to the leaflet area (normal stress). This force is supported by the lamina fibrosa layer of the leaflet and is transmitted from the collagen fibers to the cells within the tissues that are aligned with the collagen fibers. The pressure acting on the leaflets is usually estimated in terms of stresses assuming the tissue to be homogeneous [3]. In reality, the leaflet is inhomogeneous, anisotropic, nonlinear, and viscoelastic with a complex geometry.

In vivo studies using a marker-fluoroscopy technique with radiopaque markers placed on canine aortic valve leaflets were conducted as early as in 1980. The stresses were estimated from the change in position of these markers using equations for membrane stress assuming a cylindrical geometry. The membrane stresses in the circumferential direction of the leaflet were $0.167 \mathrm{kPa}$ during systole and $2.4 \mathrm{kPa}$ during diastole [3]. In another study, finite element formulation was used to analyze the stresses. Based on a pressure of $114.7 \mathrm{mmHg}$ and a human aortic valve leaflet thickness of $0.6 \mathrm{~mm}$, the maximum principle stress was found to be $2.19 \mathrm{kPa}$, which is comparable to the in vivo study [16].

3.2. Fluid Shear Stress. Aortic valve fluid shear stress is an important factor in the synthetic activity of the valvular cells and also influences cell adhesion of macrophages and other 


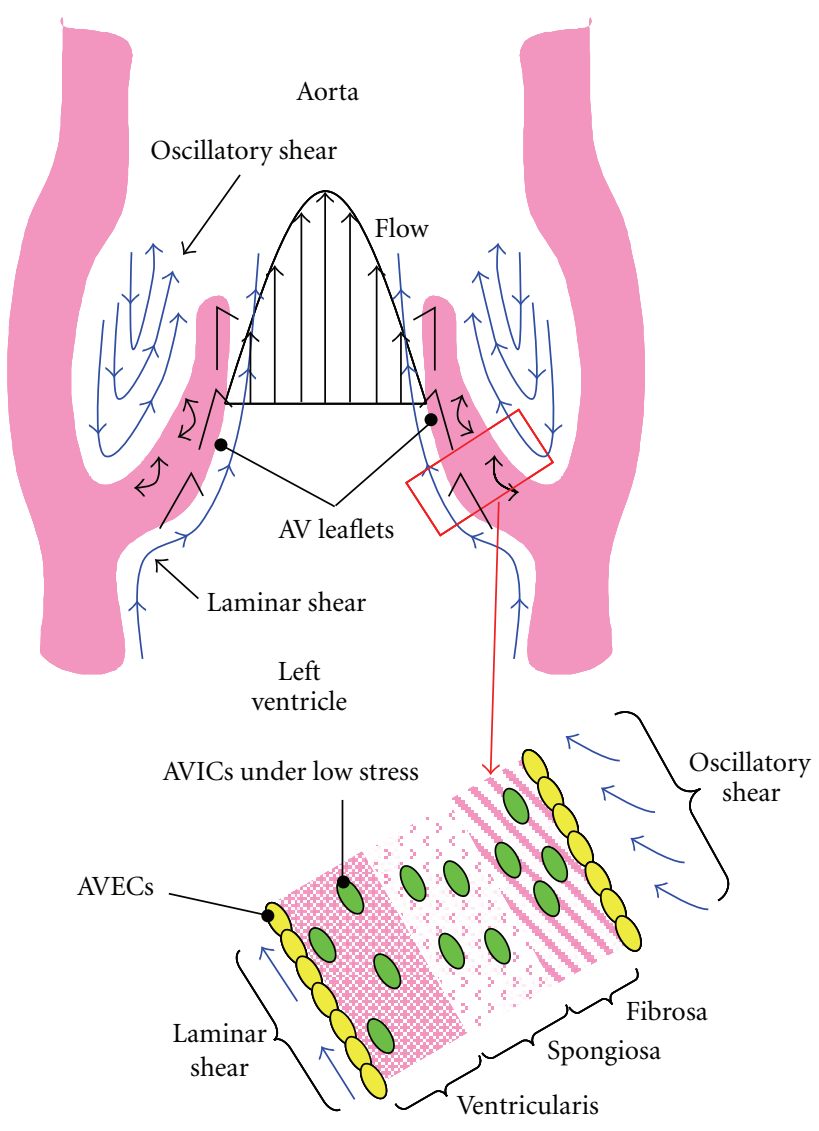

(a) Systolic mechanical forces

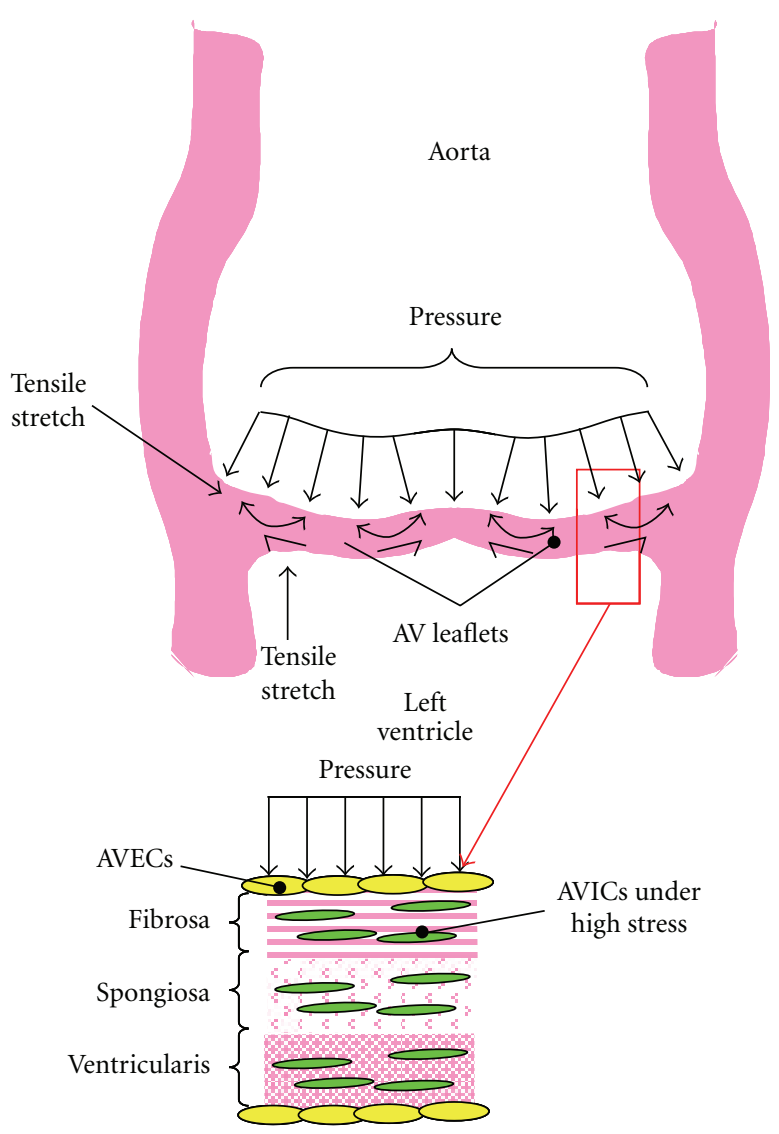

(b) Diastolic mechanical forces

FIGURE 1: Schematic of mechanical forces experienced by the aortic valve during peak systole (a), and peak diastole (b). Insets depict qualitatively the effect of these forces on valve cells.

TABLE 1: Table outlining the current state of knowledge of valve hemodynamic/mechanical parameters. Knowledge of these parameters will aid the design of in vitro or ex vivo experimental studies to study mechanobiology.

\begin{tabular}{|c|c|c|c|}
\hline Mechanical parameter & Normal & Diseased & Notes \\
\hline Pressure & $120 / 80 \mathrm{mmHg}$ & Hypertensive: $>120 />80 \mathrm{mmHg}$ & \\
\hline \multirow{2}{*}{ Membrane stress } & Systole: $0.167 \mathrm{kPa}$ & & \multirow{2}{*}[3]{} \\
\hline & Diastole: $2.4 \mathrm{kPa}$ & & \\
\hline \multirow{2}{*}{ Shear stress } & Aortic side: peak $20 \mathrm{dyn} / \mathrm{cm}^{2}$ & & \multirow{2}{*}[4,5]{} \\
\hline & Ventricular side: peak $64-71 \mathrm{dyn} / \mathrm{cm}^{2}$ & & \\
\hline Peak flow velocity & $1.20 \mathrm{~m} / \mathrm{s}$ & $7.0 \mathrm{~m} / \mathrm{s}$ (Jet-like flow) & {$[6]$} \\
\hline \multirow{2}{*}{ Bending strain and stress } & Systole: $14.5 \%$ and $1.22 \mathrm{MPa}$ & & \multirow{2}{*}[7]{} \\
\hline & Diastole: $8.3 \%$ and $0.71 \mathrm{MPa}$ & & \\
\hline \multirow{2}{*}{ Tensile strain and stress } & Circumferential: 9-11\% & Circumferential: $>15 \%$ & \multirow[t]{2}{*}{ Porcine AV [8] } \\
\hline & Radial: $13-25 \%$ & Radial: $15-31 \%$ & \\
\hline
\end{tabular}

factors in the bloodstream. Shear stress is experienced by the ventricular surface of the leaflets when blood flows past the leaflets during systole and on the aortic surface when blood pools into the sinuses during diastole. An estimate of these stresses aids in understanding the effect of stresses on leaflet cellular function and in elucidating cellular responses [17]. Due to its apparent significance to atherosclerosis, the effects of shear stress on vascular endothelial cells have been extensively studied. One of the earliest recognized effects of shear stress is the elongation and realignment of endothelial cells. Cultured endothelial cells exposed to steady laminar shear stress elongate in the direction of flow, while valvular endothelial cells align perpendicular to flow $[18,19]$. Actin stress fibers in the cytoskeleton are also 


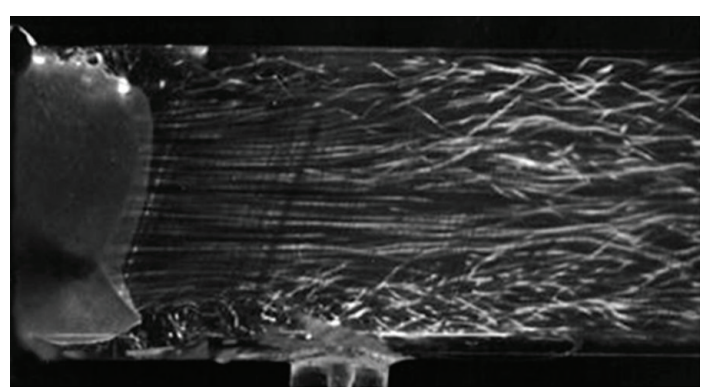

(a)

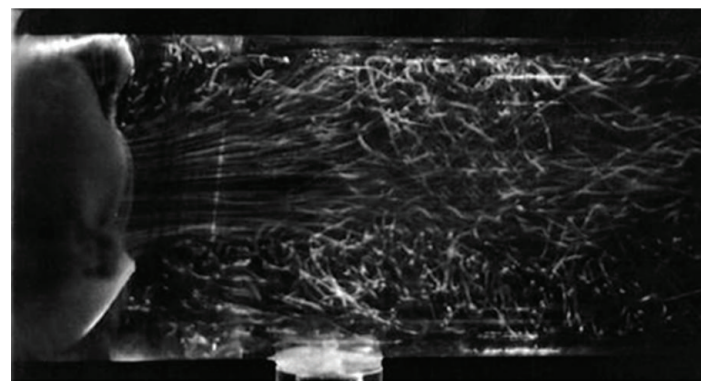

(c)
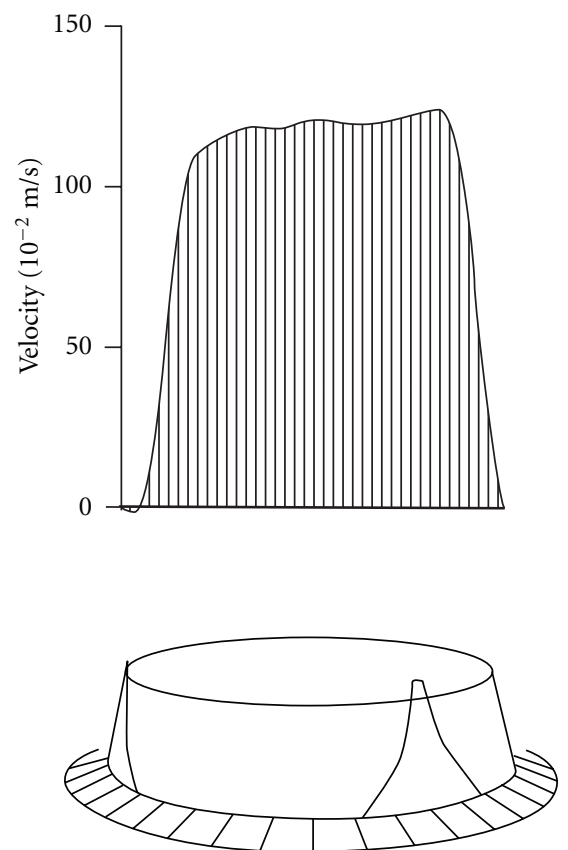

(e)

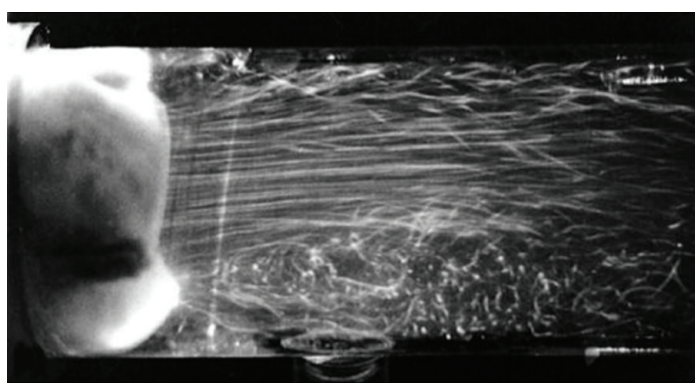

(b)

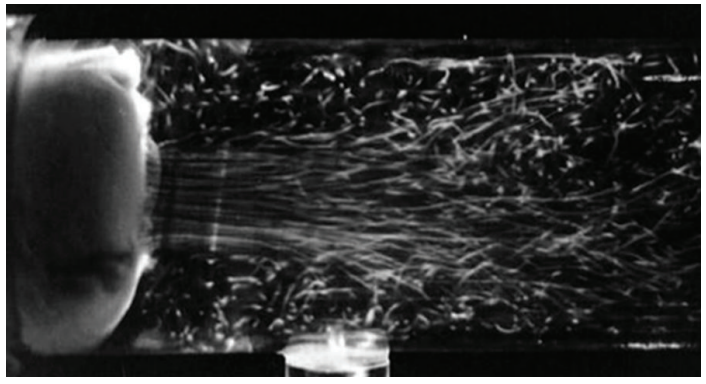

(d)
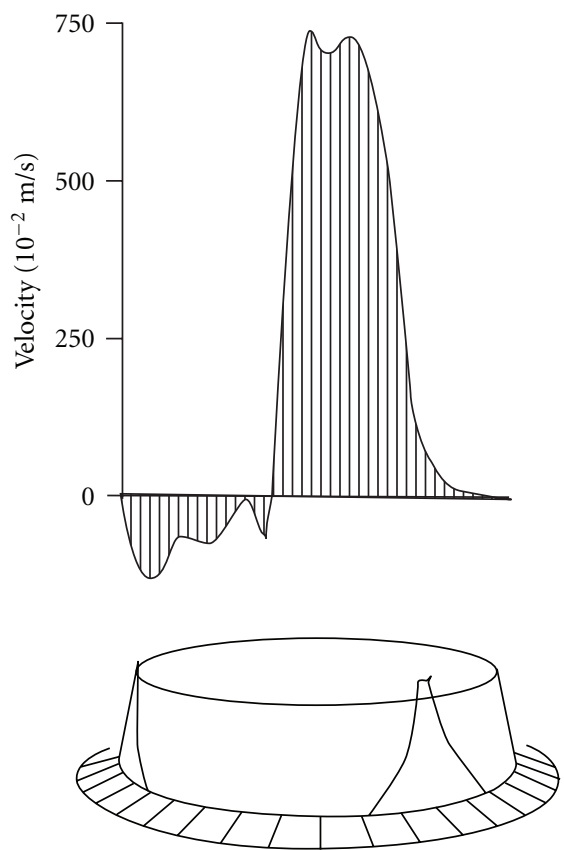

(f)

FIGURE 2: Flow patterns created at peak systole by different stenotic bioprosthetic aortic valves: (a) normal; (b) mildly stenotic; (c) moderately stenotic; (d) severely stenotic valves [6]. Schematic velocity profile at peak systole distal to (e) the normal aortic valve and (f) severely stenotic aortic valve [6].

subject to realignment with flow and increase in number with increasing shear stress [20]. Tissue degradation and failure due to calcification of the leaflets has been associated with regions of high shear and bending stresses in the leaflets during valve opening and closing [21]. Recently, Yap et al. quantified fluid shear stresses on the aortic and ventricular sides of the aortic valve leaflet and have reported differences in peak magnitudes and qualitative profiles of the shear stresses of both sides $[4,5]$.
3.3. Bending Stress. The change in leaflet curvature during the cardiac cycle gives rise to bending stresses, shearing, or buckling [3]. The collagen chords in the leaflet structure are free to bend in the circumferential direction without significant resistance from the elastic fibers aligned in the radial direction. Bending stress is both tensile and compressive with the leaflet on the convex side experiencing tensile stress while the concave side experiences compressive stress. During bending, the belly of the leaflet undergoes reversal of 
curvature due to loading and unloading of the valve while the zone of attachment acts as a hinge facilitating leaflet movement. The bending stress increases with an increase in leaflet stiffness causing early failure of some bioprosthetic valves. Thubrikar used the radiopaque marker technique to calculate the bending strains in vivo in canine aortic valves. The bending strains, calculated from modulus of elasticity, thickness and radius of the leaflet, were found to be $2 \%$ during systole and $2.2 \%$ during diastole in the circumferential direction [3]. In vitro experiments using dip-cast polyurethane trileaflet valves were performed to determine values for bending strain and stress at the free edge of the leaflet under physiological pulsatile conditions. The bending was greatest during the opening phase corresponding to a maximum strain and stress of $14.5 \%$ and $1.22 \mathrm{MPa}$, respectively. During the closing phase, the maximum strain and stress were $8.3 \%$ and $0.71 \mathrm{MPa}$, respectively [7]. It is likely that this large difference between in vitro and in vivo results is due to differing thicknesses of the canine valve leaflets and polymeric trileaflet valves, and further study is needed to accurately characterize the bending strains experienced by the valve in vivo.

3.4. Axial Stretch. Stretching is important for a cusp as it allows the cusp to extend and form a coaptive seal with the other two cusps during diastole [22-24]. It is required for the maintenance of an adequate coaptation area [22]. Leaflet stretch may be lost at a relatively rapid rate for reasons that are not yet understood [3]. The first and most rapid change starts in late adolescence. The stretch during this period is halved from $80 \%$ to $40 \%$ over a time span of 15 to 25 years. This corresponds to a linearized reduction of approximately $4 \%$ per year in stretch rate. Between the ages of 25 and 40 , the stretch remains approximately constant at a value of about $40 \%$. After the age of 40 , the stretch continues to decline at a slower linearized rate of about $1 \%$ per year until age 58 [25]. Thus, a valve from 15-year-old donor has about four times more stretch than one from a 58-year-old donor. The tissues become less extensible with increasing age because collagen fibrillogenesis increases the diameter of some of the constituent fibrils in discrete steps. Thus, larger numbers of thick collagen fibrils will require greater force to produce the same extension, causing a reduction in stretch.

In vivo studies done by Thubrikar measured the change in leaflet length in the circumferential and radial direction during the cardiac cycle in canine aortic valves. He observed that the leaflet in both the circumferential and radial directions is longer during diastole than during systole. The leaflets elongate by $11 \%$ in the circumferential direction and $31 \%$ in the radial direction from systole to diastole [3]. This is because the collagen in the circumferential direction provides greater tensile strength than that in the radial direction, which is mainly composed of elastic structures. These in vivo results agree well with the in vitro results published recently by Yap et al. [8] demonstrating circumferential strain of $11 \%$ in the circumferential direction and $28 \%$ in the radial direction. Additionally, Christie and Barratt-Boyes [25] have measured the biaxial properties of fresh and glutaraldehydefixed pulmonary and aortic valve leaflets during extension.
For the pulmonary leaflets, radial stretch was greater than that in the aortic leaflets, and circumferential stretch was similar. Thus, the ratio of radial to circumferential stretch was $6.0 \pm 1.1$ for the aortic leaflets and $9.0 \pm 1.8$ for the pulmonary leaflets. After fixation in $0.2 \%$ glutaraldehyde, the ratios in the aortic leaflets were the same except with significantly reduced stretches in both directions.

\section{Mechanobiology of Aortic Valve Remodeling, Inflammation and Calcification}

As evident now, native heart valves-the aortic and mitral valves in particular-function in a high-magnitude and complex surrounding hemodynamic environment to which the valvular structure constantly responds. The mechanical environment varies spatially and temporally over the cardiac cycle. Close correlations between mechanical stresses and heart valve biology have long been documented by clinical observations and animal studies [26-30]. The cellular and molecular events involved in these processes, however, still remain unclear. Moreover, the biological response and the mechanotransductive signaling pathways appear to be different from the extensively studied vascular cell counterparts $[19,31]$.

According to various early studies, the structural components of the aortic valve undergo constant renewal in response to mechanical loading [26], and the sites of protein and glycosaminoglycan synthesis in the leaflets correlate with the areas of functional stress [27]. Changes in mechanical loading in turn alter the biosynthetic behavior of valve cells. For example, collagen synthesis in mitral valve leaflets was enhanced as a result of altered stress distribution due to left ventricular infarctions [32]. Other studies indicate that abnormal hemodynamics experienced by the valve leaflets cause tissue inflammation, which can lead to calcification, stenosis, and ultimate valve failure [33-37]. The common feature in valvulopathy appears to be the expression of an activated myofibroblast phenotype in the valve interstitium [38], which is absent in the quiescent leaflet, but abundant during disease initiation and progression $[39,40]$. The expression of particular phenotypes of valvular endothelial and interstitial cells appears to depend not only on a combination of intrinsic genetically programmed biology, but also on local hemodynamic environmental factors, one family of which is the stresses induced by blood flow and structural strain due to leaflet deformation. It is therefore hoped that a detailed understanding of valve mechanobiology and disease regulation will allow development of better treatment options for valve disease.

Traditional benchtop studies can be categorized as either ex vivo or in vitro studies. In vitro studies approach the biological problem at the cell level and have tremendous utility in elucidating signaling mechanisms. However, in the valve where several cell types exist, paracrine signaling between endothelial and interstitial cells is key, and in vitro single-cell studies are limited in their ability to explain. It is only recently that advances are being made in developing $2 \mathrm{D}$ and $3 \mathrm{D}$ in vitro coculture models for the valve [41]. 
Also, critical cell-extracellular matrix interactions cannot be holistically modeled in vitro. Ex vivo whole-tissue studies can fill this critical gap.

Bioreactors are the standard means of imposing mechanical forces on cells or tissues. Commercially available ones include the Flexercell series of tension, compression, or flow devices that are primarily used for cells in culture. Several research groups have also designed customized bioreactors for the culture of sections of valve tissue or the whole valve apparatus. These include devices to subject tissues to stretch, shear stresses [42], bending stresses [43], and pressure [44, 45]. More recently, bioreactors subjecting valve tissue to combined mechanical forces $[43,46]$ and "benchtop heart simulators" [47-49] that subject the entire valve explant to hemodynamic forces have become more prevalent. The following sections discuss key findings from benchtop in vitro and ex vivo work on the pathological changes experienced by the aortic valve exposed to various hemodynamic stimuli organized by the different mechanical forces.

4.1. Effect of Static and Pulsatile Pressure. The effects of pressure on cultured cells have been studied extensively with vascular endothelial cells, smooth muscle cells, cartilage chondrocytes, and other cell types [50-54]. The affected properties include cell proliferation, apoptosis, synthetic activity, and gene expression, suggesting that the effects of pressure on cellular function are complex. Also, there was evidence of two different mechanoregulatory mechanisms for static and pulsatile pressures as indicated by the work of Sukhova et al. [54]. The effects of changes in static and pulsatile cyclic pressure have been investigated on whole valve tissue using pressurized chamber bioreactors. For the most part, either compressed air or a piston was used to alter the pressure within the pressurized chamber in a controlled manner. Xing et al. investigated the effects of static and cyclic pressure on aortic valve cusps with a focus on pressure magnitude and pulse frequency [44]. A wide range of pressures $(80-120,120-160$, and $150-190 \mathrm{mmHg})$ and pulse frequencies $(0.5,1.167$, and $2 \mathrm{~Hz})$ were studied. Elevated static pressure caused an increase in collagen synthesis that was more significant at elevated pressures, while no significant difference in DNA or sGAG synthesis was observed. A notable decline in $\alpha$-SMA, a standard marker for valve interstitial cell activation, was observed over the course of these experiments although no significant difference was observed between the pressure and control groups. It was concluded that elevated pressure caused a proportional increase in collagen synthesis of porcine aortic valve leaflets and had a downward effect on valve cell activation. Culture under pulsatile pressure revealed that increases in pressure magnitude (with the frequency fixed at $1.167 \mathrm{~Hz}$ ) resulted in significant increases in both collagen and sulfated glycosaminoglycan (sGAG) synthesis, while DNA synthesis remained unchanged. Responses to pulse frequency (with the mean magnitude fixed at $100 \mathrm{mmHg}$ ) were more complex. Collagen synthesis and sGAG synthesis were increased at $0.5 \mathrm{~Hz}$, but were not affected at 1.167 and $2 \mathrm{~Hz}$. In contrast, DNA synthesis increased at $2 \mathrm{~Hz}$, but not at 0.5 and $1.167 \mathrm{~Hz}$. Under extreme hypertensive pressure conditions $(170 \mathrm{mmHg}, 2 \mathrm{~Hz})$, collagen synthesis and sGAG synthesis were increased but to a lesser degree than at $170 \mathrm{mmHg}$ and $1.167 \mathrm{~Hz}$. As with the static pressure studies, a notable decline in $\alpha$-SMA was observed over the course of the experiments. In a subsequent study, Warnock et al. [55] reported significant increases in VCAM-1 expression under elevated pressures suggesting an early inflammatory response.

These results suggest that cyclic pressure affects biosynthetic activity of aortic valve leaflets in a magnitude- and frequency-dependent manner. Collagen synthesis and sGAG synthesis were positively correlated and more responsive to pressure magnitude than pulse frequency. DNA synthesis was more responsive to pulse frequency than pressure magnitude. However, when combined, pressure magnitude and pulse frequency appeared to have an attenuating effect on each other. Intriguingly, the activated contractile phenotype of the valve interstitial cell, measured by $\alpha$-SMA expression, was not expressed when cultured under isolated pressure. Taken together, an observed increase in proinflammatory expression suggests an important role for transvalvular pressure in mediating valve disease and valve cell activation.

4.2. Effect of Fluid Shear Stress. Early studies primarily focused on the effects of steady shear stress on aortic valve biology [56]. These studies were mostly conducted in parallel plate chamber bioreactors and reported that steady shear stress altered the biosynthetic activity of aortic valve cusps and was unable to preserve $\alpha$-SMA expression in cells [56]. Although the cellular mechanisms triggering this specific response to shear stress were not well understood, it was hypothesized that the valvular endothelium plays an important role. Butcher et al. [19] reported that valve endothelial cells aligned parallel to steady, laminar flow in contrast with vascular endothelial cells, underscoring the difference between these two cell types. It was also postulated that aortic valve endothelial cells cocultured with smooth muscle cells can affect the properties of smooth muscle cells through the release of paracrine factors [41]. Ex vivo experiments from the Yoganathan lab demonstrated that valvular responses to shear in the absence of an endothelium were remarkably different from responses of intact leaflets (Figure 3). Collagen synthesis in the intact leaflets was enhanced under shear stress, but not changed in the endothelium-denuded leaflets at the same shear stress; sGAG content was not affected by shear stress in the intact leaflets, but was upregulated by shear stress in the denuded leaflets. These results indicate that aortic valve interstitial cells respond to shear stress in the absence of aortic valves' endothelial cells, but the presence of aortic valves' endothelial cells mediates these responses.

Matrix metalloproteinases and cathepsins are known to play an important role in the remodeling of various types of tissues and are often expressed early in the disease progression of aortic valves $[57,58]$. This was demonstrated elegantly using molecular imaging by Aikawa et al. [59]. Cathepsin L activity has been shown to decrease in response to steady laminar shear stress [60]. Since the function of cathepsin $\mathrm{L}$ is to degrade collagen, the observed higher 


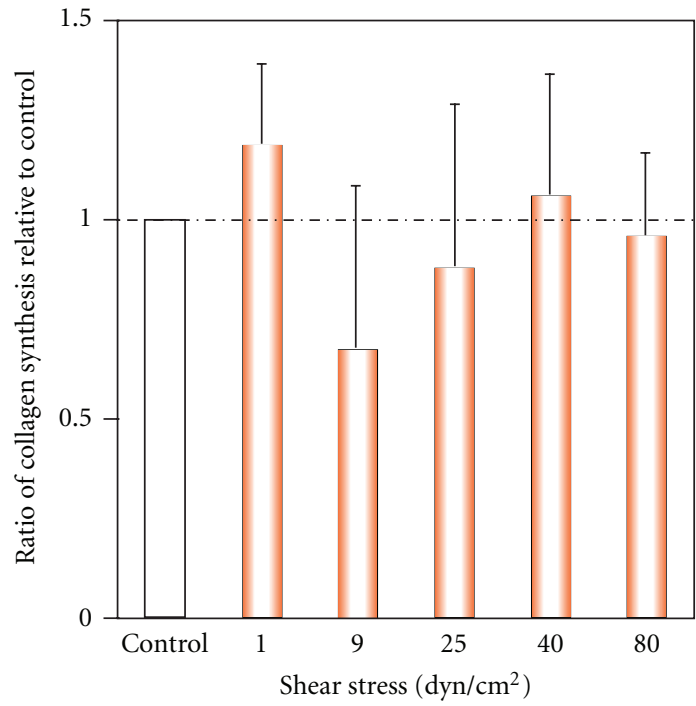

(a)

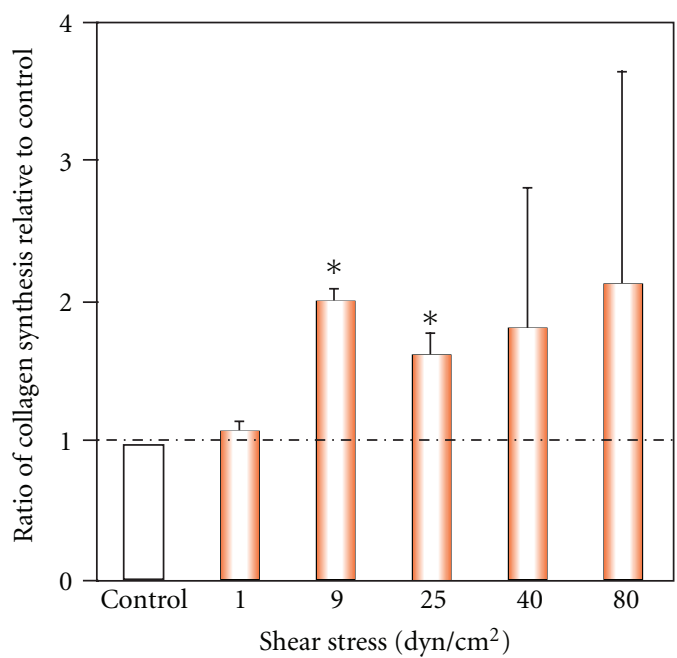

(c)

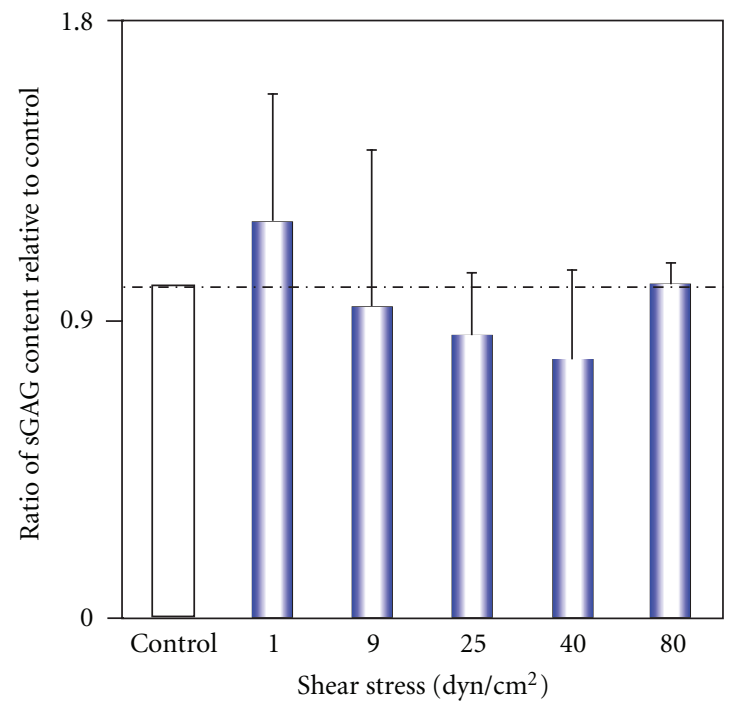

(b)

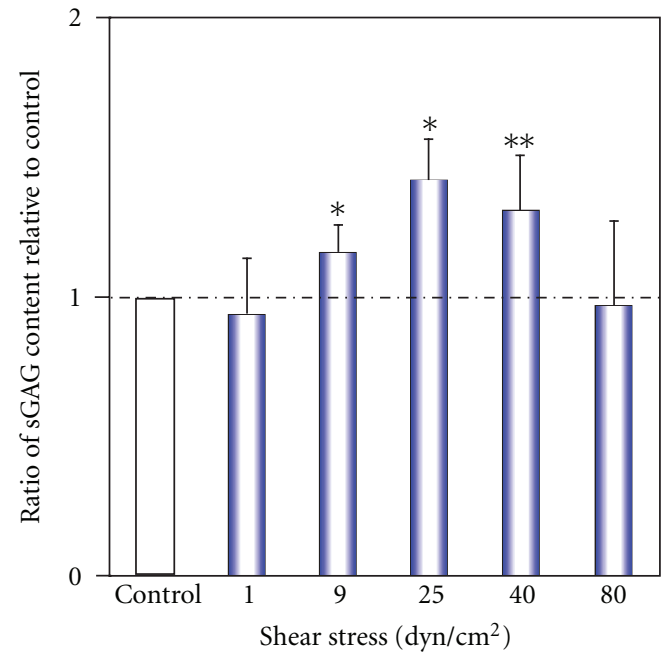

(d)

FIGURE 3: Effects of steady shear stress on aortic valve biology. Collagen synthesis and sulfated glycosaminoglycan content in intact (a and b, resp.) and denuded (c and d, resp.) aortic valve leaflets under steady shear stress.

collagen content under shear stress conditions is likely due, at least partly, to an increase in the overall collagen content due to a downregulation of the degradation process. The resulting collagen pool in the valve tissue is therefore a dynamic balance between new synthesis and degradation by collagenases such as cathepsins, which are regulated by mechanical factors such as shear stress. In addition, the inhibitory effects of shear stress on cathepsin L activity do not seem to depend on the presence of an intact endothelium as suggested by an ex vivo study [60]. The reduction of cathepsin L activity in endothelium-denuded leaflets is almost similar to that observed in intact leaflets exposed to fluid shear stress. This implies that the shear stress regulation of cathepsin activity might be achieved through a pathway that does not require the participation of the endothelium.

Shear stress is also an important hemodynamic force that directly regulates inflammation, calcification, and ossifi- cation, which are common features of aortic valve diseases $[52,53,61]$. Although the events leading to these disease states share some similarities with bone miner-alization [34, 54], their molecular mechanisms remain vastly understudied [62]. Aortic valve diseases preferentially occur on the aortic side of the valvular leaflets where they are exposed to complex and unstable hemodynamic conditions $[58,63]$. The reasons for this side-specific response potentially associated with the local shear stress environment are not completely understood. Although many studies have been carried out to characterize the response of vascular endothelial cells to shear stress [64, 65], studies on valvular endothelial cells are few. The exposure of valvular endothelium to steady unidirectional shear stress has been shown to result in the alignment of the endothelial cells perpendicularly to the flow whereas vascular endothelial cells align parallel to the flow [19]. In addition, the transcriptional profiles of both 
Fresh tissue
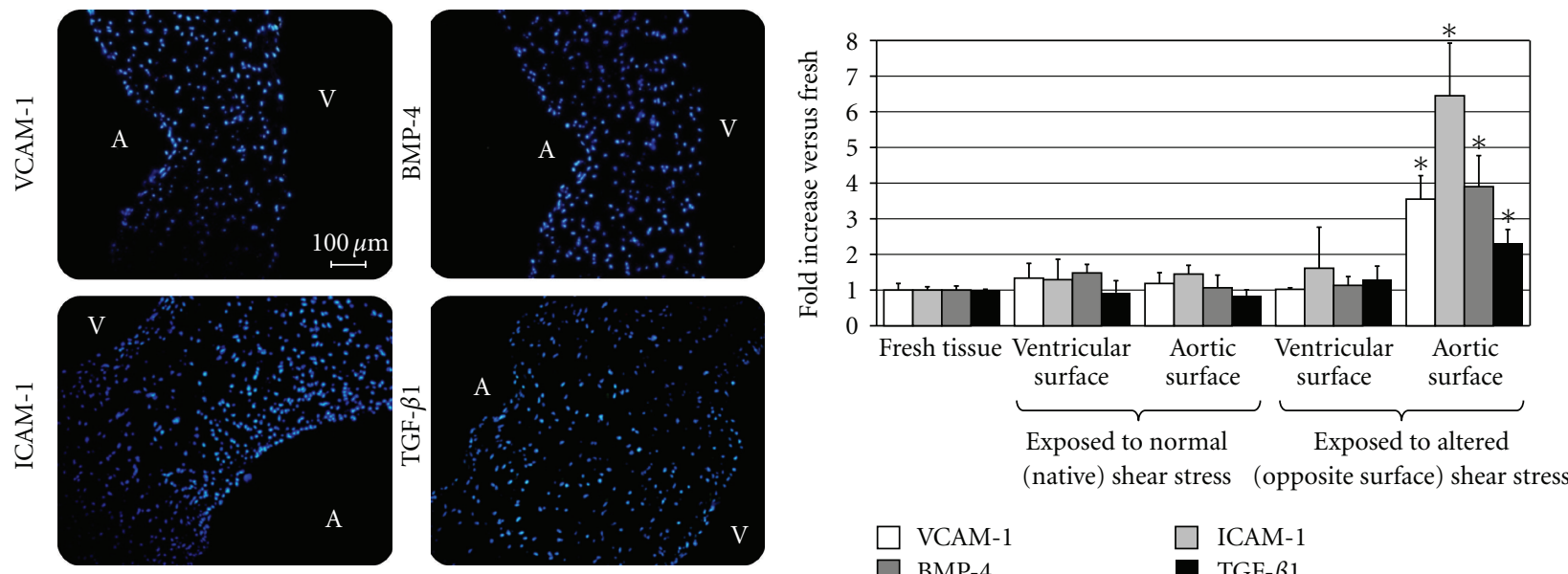

(a)

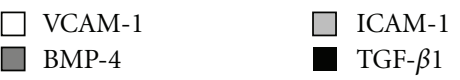

(b)

Aortic surface exposed to native shear stress
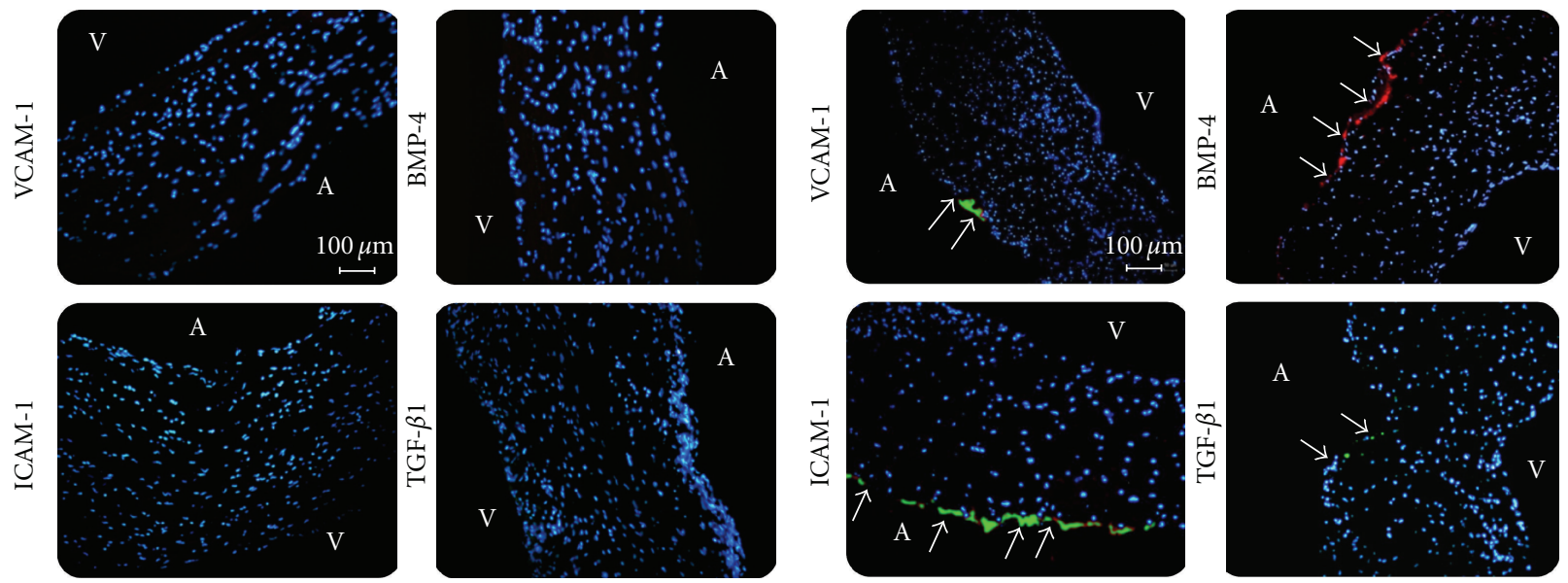

(c)

(d)

FIGURE 4: Inflammatory response of AV leaflets after exposure of the fibrosa to normal (native) and altered (ventricular) shear stress: immunostaining (blue: cell nuclei; green: ICAM-1/VCAM-1/TGF- $\beta 1$; red: BMP-4); quantitative results $\left({ }^{*} P<.05\right.$ versus fresh).

cell types have been compared under static and shear stress conditions, and up to $10 \%$ of the genes considered in that study were found to be significantly different [66], suggesting clear phenotypic differences between these two cell types in response to shear stress. Despite those differences, it has been shown that the pathological inflammatory responses of the two cell types involve similar mediators such as vascular cell adhesion molecule-1 (VCAM-1) and intracellular adhesion molecule-1 (ICAM-1) [67]. In the context of the valvular response, these mediators are expressed preferentially on the aortic side of the leaflet. In addition to this side specificity, aortic valve calcification and inflammation are associated with the expression of transforming growth factor-betal (TGF- $\beta 1$ ) [68]. TGF- $\beta 1$ is a polypeptide member of the TGF- $\beta$ superfamily which consists of TGF- $\beta$ s, inhibins, bone morphogenic proteins (BMPs), growth differentiation factors, anti-Mullerian hormone, activins, and myostatin [69]. TGF- $\beta 1$ has been shown to trigger calcification in sheep aortic valve interstitial cells by increasing alkaline phosphatase activity [70]. Although cell and clinical studies have suggested a potential role for TGF- $\beta 1$ in the initiation and progression of calcification in aortic valve interstitial cells, studies at the tissue level are lacking. In addition, although it has been shown that exposure of vascular endothelial cells to oscillatory shear stress induces inflammatory responses by the BMP-dependent mechanisms [71, 72], it is not clear whether BMP plays a role in inflammatory responses in aortic valve leaflet in response to altered mechanical environment.

Sucosky et al. studied the effects of pulsatile and oscillatory shear stresses on aortic valve leaflet samples in a modified cone-and-plate bioreactor $[42,73]$. The main objective of this study was to understand the effect of altered hemodynamics on aortic valve cellular response. Exposure of the aortic surface to pulsatile shear stress (i.e., the nonphysiological or altered hemodynamic force) increased the 


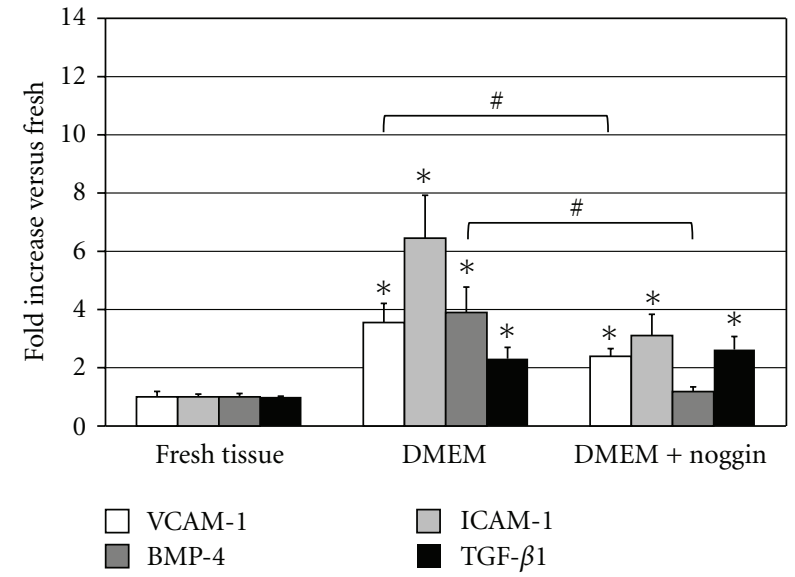

(a)

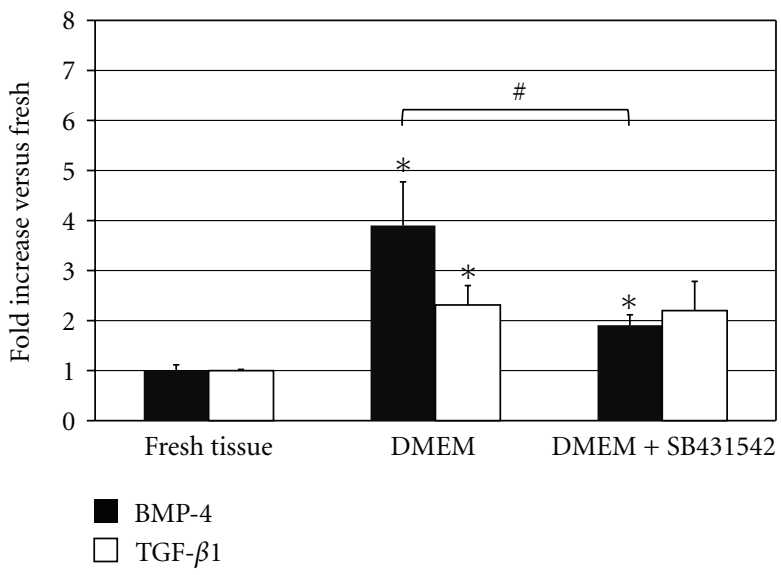

(b)

Figure 5: Cytokine and cell-adhesion molecule expressions after exposure of the fibrosa to altered shear stress in culture medium supplemented with (a) noggin and (b) SB-431542 ( ${ }^{*} P<.05$ versus fresh; $\left.{ }^{*} P<.05\right)$.

expression of the inflammatory markers (Figure 4). In contrast, neither pulsatile nor oscillatory shear stress affected the expression of the inflammatory markers on the ventricularis surface. The shear-stress-dependent expression of VCAM1, ICAM- 1 , and BMP-4, but not TGF- $\beta 1$, was significantly reduced by the BMP inhibitor noggin, whereas the TGF- $\beta 1$ inhibitor SB431542 blocked BMP-4 expression (Figure 5) on the aortic surface exposed to pulsatile shear stress. These results therefore demonstrate that altered hemodynamics stimulates the expression of AV leaflet endothelial adhesion molecules in a TGF- $\beta 1$ - and BMP-4-dependent manner, providing some potential directions for future drug-based therapies for AV diseases.

As an extension of this work, another ex vivo study investigated the isolated effects of alterations in shear stress magnitude on valvular endothelial activation [74]. The fibrosa of porcine leaflets was subjected to subphysiologic, physiologic, and supraphysiologic magnitudes of native oscillatory shear stress in the same cone-and-plate apparatus. Under mild and severe supra-physiologic shear stress conditions, VCAM-1 and ICAM-1 expressions were observed on the endothelial lining of the fibrosa while positive BMP- 4 and TGF- $\beta 1$ staining was detected in both the endothelial and subendothelial layers (Figure 6(a)). In contrast, exposure of the fibrosa to physiologic and subphysiologic shear stress did not elicit any positive staining. Those results demonstrate the shear stress magnitude dependence on the leaflet pathological state in response to hemodynamic alterations. In addition, the synergistic effects of BMP- 4 and TGF- $\beta 1$ in shear stressinduced valvular endothelial activation were investigated by silencing those cytokines through the use of a culture medium supplemented with both the BMP antagonist noggin and the TGF- $\beta 1$ inhibitor SB-431542. Under supra physiologic shear stress, the combined noggin + SB- 431542 treatment significantly reduced cytokine and cell-adhesion molecule expressions as compared to the levels measured in tissue exposed to similar conditions in standard medium and brought them back to the levels measured in fresh controls
(Figure 6(b)). Those results demonstrate that (1) exposure of the fibrosa to supra-physiologic shear stress stimulates cytokine and cell-adhesion molecule expression within 48 hours, (2) BMP-4 and TGF- $\beta 1$ interact to synergistically regulate endothelial activation in response to elevated shear stress, and (3) TGF- $\beta 1$ plays a dominant role in the shearstress-induced pathological response of AV leaflets.

4.3. Effects of Cyclic Stretch. As mentioned before, cyclic stretch is one of the forces experienced by the aortic valve during the cardiac cycle that allows the valve cusps to extend and form a coaptive seal during diastole $[22,23]$. The valve, under normal physiological conditions, experiences approximately $10 \%$ stretch during diastole $[3,75]$. Utilizing an in vitro flow loop and a native porcine aortic valve, Yap et al. have demonstrated that for every $40 \mathrm{mmHg}$ increase in pressure, there is a $5 \%$ increase in cyclic stretch [8]. The effects of cyclic stretch on the aortic valve have been investigated on valve cells as well as on whole valve tissue. Most in vitro studies have been conducted using the Flexercell device and primarily as single-cell models studying either the endothelial or interstitial cell [76-78]. In vitro coculture models for cyclic stretch have been lacking, while custom made bioreactors have been used to study the whole valve. One such device is the tensile stretch bioreactor, which has been used to culture whole valve samples under a defined stretch waveform [79-81].

Batten et al. reported that cyclic stretch upregulated collagen synthesis in valve interstitial cells as well mesenchymal stem cells [78], which was also demonstrated recently by Balachandran et al. on whole valve cusps utilizing the aforementioned tensile stretch bioreactor [79]. This study reported that collagen content increased with increasing stretch, while sGAG content was reduced. Cyclic stretch also was shown to upregulate the contractile phenotype of interstitial cells, which is in contrast to the result from the pressure studies. In addition, stretch studies suggest that $\alpha$-smooth muscle actin is preferentially expressed on the 


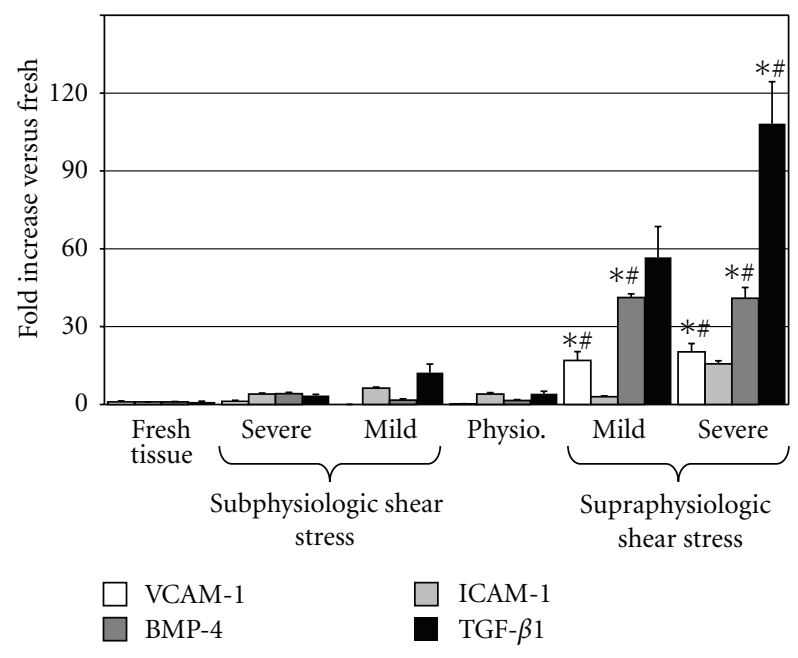

(a)

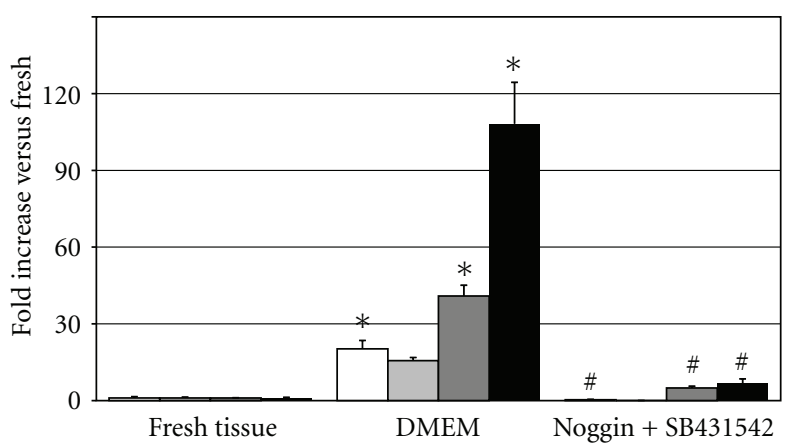

(b)

Figure 6: Cytokine and cell-adhesion molecule expressions after exposure of the fibrosa to (a) various shear stress magnitudes $\left({ }^{*} P<.05\right.$ versus fresh; ${ }^{\#} P<.05$ versus physiologic/subphysiologic) and (b) severe supraphysiologic shear stress in medium supplemented with SB431542 and noggin $\left({ }^{*} P<.05\right.$ versus fresh; ${ }^{\#} P<.05$ versus standard medium (DMEM)).

ventricular side of the stretched aortic valve leaflet [79]. Merryman et al. reported that valve interstitial cells respond to local tissue stresses by altering cellular stiffness via collagen biosynthesis [82]. Indeed, it has been suggested that valve stiffness may be an important regulator of calcification [83]. Hopkins et al. also reported that the presence of cytokines such as TGF- $\beta 1$ in a cyclic stretch environment could potentially result in altered matrix architecture and compromised valve function, underlining the importance of cyclic stretch in regulating valve structure, function, and disease progression [81].

Aortic stenosis and regurgitation, which are clinical manifestations of aortic valve disease, have been correlated in several patients with overexpression of proteolytic enzymes such as matrix metalloproteinases (MMPs), their tissue inhibitors (TIMPs), and cathepsins [84]. During normal homeostasis in the aortic valve, there is balance between extracellular matrix biosynthesis and degradation maintained by these enzymes [85]. A perturbation of this delicate equilibrium can lead to pathological remodeling of the tissue matrix and compromised valve function [84]. A number of these cathepsins, MMPs and TIMPs, are also involved in key cellular processes such as apoptosis, proliferation, and cell differentiation and have demonstrated roles in valve disease pathways [86]. Cathepsins $\mathrm{K}, \mathrm{L}$, and $\mathrm{S}$, which are potent elastolytic proteases, have been associated with atherosclerotic plaque progression [53] and myxomatous heart valves [87].

Sucosky et al. [80] studied the effects of three levels of cyclic stretch (10\%-physiologic, $15 \%$-pathologic, $20 \%$ hyperpathologic) on aortic valve extracellular matrix remodeling in porcine aortic valves with a focus on the aforementioned MMPs, TIMPs, and cathepsins. Immunohistochemical staining revealed that Cathepsin $\mathrm{S}$ and $\mathrm{K}$ expressions were upregulated by $15 \%$ cyclic stretch, while Cathepsin L expression was downregulated when compared with controls. Gelatin zymography and reverse zymography revealed modulation of MMP and TIMP activity in a time- and magnitude-dependent manner. TIMP activity was reduced significantly by all levels of cyclic stretch when compared with fresh controls. Collagenase activity was increased significantly compared to fresh controls after $15 \%$ and $20 \%$ stretch. These results suggest that activity of certain proteolytic enzymes (Cathepsin S, K, MMP-2,9) may be mechanosensitive and have an important role in the progression of valvulopathy under altered mechanical loading.

Probing deeper into the mechanisms behind stretchinduced valve disease, we sought to understand the effects of stretch on calcification in valve tissue [88]. Utilizing an osteogenic medium to stimulate rapid valve inflammation and calcification on the benchtop, Balachandran et al. observed that tissue mineralization occurred in a stretchmagnitude-dependent manner, which was inhibited by the bone morphogenic protein antagonist noggin, in a nogginconcentration-dependent manner. These results therefore highlight that as in fluid shear stress, valve inflammation and calcification are modulated by cytokines such as TGF$\beta 1$ and BMP-4 and that the signaling pathways induced by these molecules can be highly mechanosensitive. Smith et al. [77] reported the anti-inflammatory effects of cyclic strain on aortic valve interstitial cells. The apparent difference with the results reported by Balachandran et al. is thought to be due to the lack of endothelial cells in the former study, highlighting the importance of endothelial-interstitial cell crosstalk. Additionally, Ferdous et al. [89] demonstrated that stretch-induced mechanisms for valve interstitial cells differ from those of vascular smooth muscle cells. Further study in this area is therefore required to identify unique target candidate molecules for gene and molecular therapy in order to prevent or slow down valve inflammatory disease. 


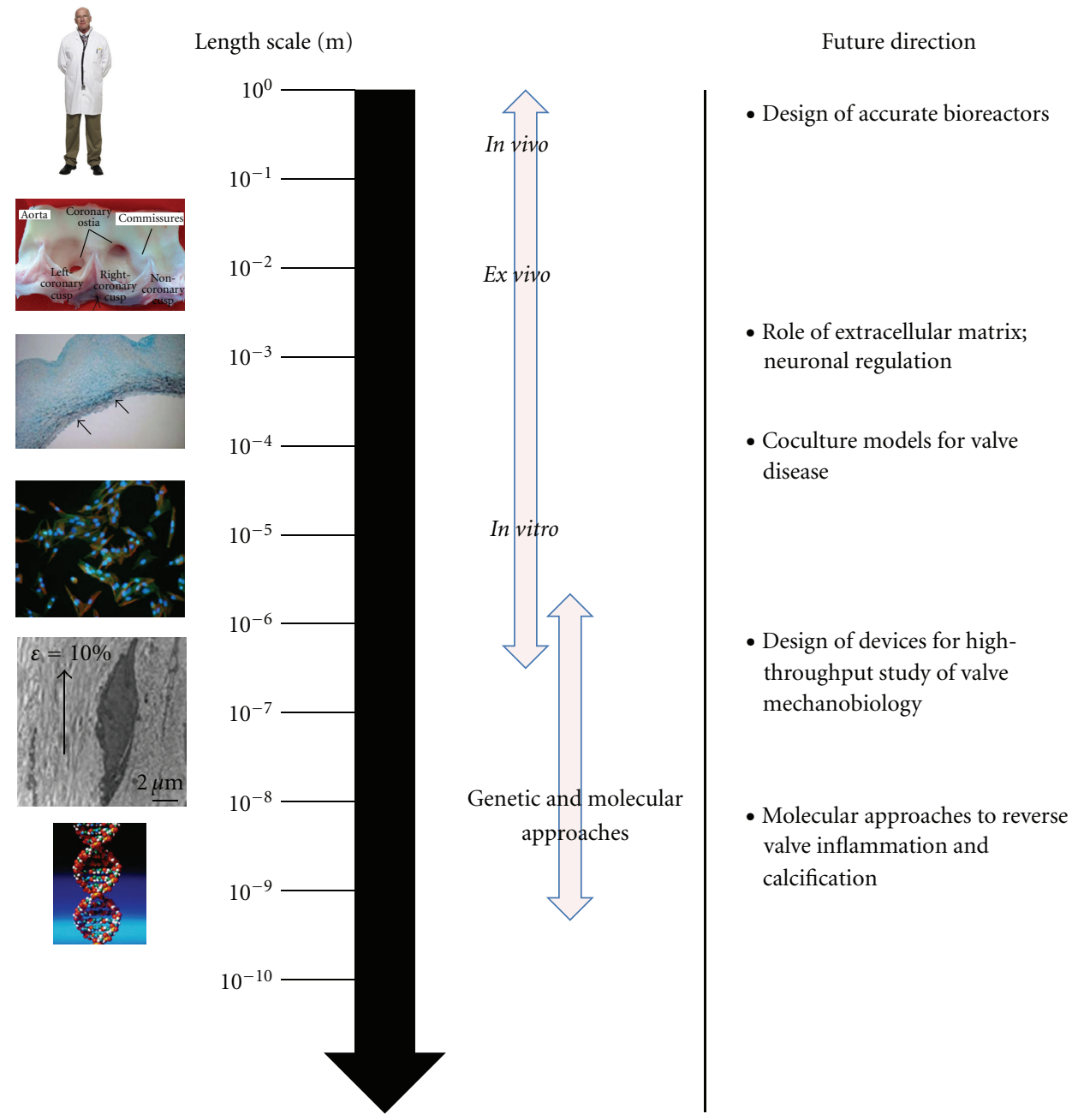

FIGURE 7: Multiscale, hierarchical approach that is recommended for approaching the study of valve mechanobiology and mechanopathology.

4.4. Complex Loading Regimes. Due to the complex interplay among the various mechanical forces experienced by the valve, there has been a much needed trend towards the design of novel bioreactors that can simulate combined mechanical forces on valve tissue. Engelmayr et al. developed the flexstretch-flow bioreactor to study the combined effects of bending, stretch, and shear stress on tissue samples [43]. Thayer et al. developed a stretch-pressure bioreactor and reported the nonsynergistic regulation of aortic valve cell phenotype by the two mechanical forces (i.e., opposing effects of stretch versus pressure), suggesting the importance of the combined gamut of mechanical stimulation for the maintenance of the valve phenotype [46]. Indeed, Xing et al. demonstrated the need for all the in vivo mechanical forces in the normal homeostatic maintenance of the valve [90]. Recently, Barzilla et al. developed a novel splashing bioreactor [49] for the mitral valve that also demonstrated the importance of mechanical stimulation for normal cardiac valve function. The same group also demonstrated the utility of these whole organ culture models in studying serotonergic valve disease [48]. Taken as a whole, it appears that the response of the valve to combined mechanical stimulation is not just a simple sum of the effects of each of the individual forces, but a more complex response.

\section{Summary and Future Direction}

It is evident that the field has made tremendous progress toward understanding the mechanoresponse of valve cells and how it relates to disease. Research into the mechanobiology of cardiac valve disease is relatively recent, and we are only now beginning to get a deeper understanding of the complex interplay between valve cells, the extracellular matrix, and the surrounding mechanical environment. Early work was focused on understanding the mechanical environment and developing bioreactors to perform benchtop studies. Future work must devote greater attention to detail in the design of accurate bioreactors that simulate the combined mechanical forces of the native tissue environment. Coculture (interstitial and endothelial cells) in vitro models also need to be further explored [91], as ex vivo studies alone cannot provide the level of detail in the 
mechanoregulation of signaling pathways. Additionally, the role of the extracellular matrix [83] and potential neuronal regulation $[12,92]$ of valve function has emerged as important in the interplay between valve structure, mechanics, and function and should not be overlooked. With the goal of developing pharmacological and gene therapies for valve inflammation and calcification, there is also a dire need for devices that can perform high-throughput testing of valve cells or tissues and their mechanobiological responses. Moraes et al. demonstrate such a device while probing for the mechanoregulation of wnt/ $\beta$-catenin signaling in valve cells [93]. In addition, new evidence for regional/focal variation in valve mechanics [94] has potential implications for understanding the regional variation of cellular response to these varied mechanical stimuli. Finally, we currently have no way of reversing the effects of valve calcification once diagnosed. Heart valve replacement is often the only option for these patients, and it would be extremely valuable to be able to apply findings from the mechanobiology towards the development of therapies that can stimulate the cells to resorb or degrade calcific lesions.

It has become clear as we delve deeper in our understanding of valve mechanobiology that an interdisciplinary, hierarchical approach (Figure 7) toward its study is required. Approaches based on the intersection of biology, mechanics, bioinformatics, and micro/nanoengineering among others are key. Intimate crosstalk between the different length scales will allow for a complete understanding of the mechanoresponse of the valve. With this understanding, one can work towards the ultimate goal of developing treatments and functional replacements for diseased valves.

\section{References}

[1] C. M. Otto, "Evaluation and management of chronic mitral regurgitation," New England Journal of Medicine, vol. 345, no. 10, pp. 740-746, 2001.

[2] H. Reul and N. Talukder, "Heart valve mechanics," in Quantitative Cardiovascular Studies Clinical and Research Applications of Engineering Principles, N. H. C. Hwang, D. R. Gross, and D. J. Patel, Eds., pp. 527-564, University Park Press, Baltimore, Md, USA, 1979.

[3] M. Thubrikar, The Aortic Valve, CRC Press, Boca Raton, Fla, USA, 1990.

[4] C. H. Yap, N. Saikrishnan, G. Tamilselvan, and A. P. Yoganathan, "Experimental measurement of dynamic fluid shear stress on the aortic surface of the aortic valve leaflet," Biomechanics and Modeling in Mechanobiology.

[5] C. H. Yap, N. Saikrishnan, and A. P. Yoganathan, "Experimental measurement of dynamic fluid shear stress on the ventricular surface of the aortic valve leaflet," Biomechanics and Modeling in Mechanobiology.

[6] A. P. Yoganathan, "Fluid mechanics of aortic stenosis," European Heart Journal, vol. 9, supplement E, pp. 13-17, 1988.

[7] J. Corden, T. David, and J. Fisher, "In vitro determination of the curvatures and bending strains acting on the leaflets of polyurethane trileaflet heart valves during leaflet motion," Proceedings of the Institution of Mechanical Engineers, vol. 209, no. 4, pp. 243-253, 1995.

[8] C. H. Yap, H. S. Kim, K. Balachandran, M. Weiler, R. Haj-Ali, and A. P. Yoganathan, "Dynamic deformation characteristics of porcine aortic valve leaflet under normal and hypertensive conditions," American Journal of Physiology, vol. 298, no. 2, pp. H395-H405, 2010.

[9] P. J. Kilner, G. Z. Yang, R. H. Mohiaddin, D. N. Firmin, and D. B. Longmore, "Helical and retrograde secondary flow patterns in the aortic arch studied by three-directional magnetic resonance velocity mapping," Circulation, vol. 88, no. 5, part 1, pp. 2235-2247, 1993.

[10] H. W. Sung and A. P. Yoganathan, "Axial flow velocity patterns in a normal human pulmonary artery model: pulsatile in vitro studies," Journal of Biomechanics, vol. 23, no. 3, pp. 201-214, 1990.

[11] M. H. Yacoub and L. H. Cohn, "Novel approaches to cardiac valve repair: from structure to function: part I," Circulation, vol. 109, no. 8, pp. 942-950, 2004.

[12] I. El-Hamamsy, K. Balachandran, M. H. Yacoub et al., "Endothelium-dependent regulation of the mechanical properties of aortic valve cusps," Journal of the American College of Cardiology, vol. 53, no. 16, pp. 1448-1455, 2009.

[13] A. H. Chester, "Endothelin-1 and the aortic valve," Current Vascular Pharmacology, vol. 3, no. 4, pp. 353-357, 2005.

[14] A. H. Chester, M. Misfeld, H. H. Sievers, and M. H. Yacoub, "Influence of 5-hydroxytryptamine on aortic valve competence in vitro," Journal of Heart Valve Disease, vol. 10, no. 6, pp. 822-826, 2001.

[15] A. H. Chester, M. Misfeld, and M. H. Yacoub, "Receptormediated contraction of aortic valve leaflets," Journal of Heart Valve Disease, vol. 9, no. 2, pp. 250-255, 2000.

[16] Cataloglu, Phillip L. Gould, and Richard E. Clark, "Refined stress analysis of human aortic heart valves," Journal of the Engineering Mechanics Division, vol. 102, no. 1, pp. 135-150, 1976.

[17] M. W. Weston, D. V. LaBorde, and A. P. Yoganathan, "Estimation of the shear stress on the surface of an aortic valve leaflet," Annals of Biomedical Engineering, vol. 27, no. 4, pp. 572-579, 1999.

[18] C. L. Ives, S. G. Eskin, and L. V. McIntire, "Mechanical effects on endothelial cell morphology: in vitro assessment," In Vitro Cellular \& Developmental Biology, vol. 22, no. 9, pp. 500-507, 1986.

[19] J. T. Butcher, A. M. Penrod, A. J. García, and R. M. Nerem, "Unique morphology and focal adhesion development of valvular endothelial cells in static and fluid flow environments," Arteriosclerosis, Thrombosis, and Vascular Biology, vol. 24, no. 8, pp. 1429-1434, 2004.

[20] A. J. Wong, T. D. Pollard, and I. M. Herman, "Actin filament stress fibers in vascular endothelial cells in vivo," Science, vol. 219, no. 4586, pp. 867-869, 1983.

[21] D. J. Wheatly, J. Fisher, and I. J. Reece, "Primary tissue failure in pericardial heart valves," Journal of Thoracic and Cardiovascular Surgery, vol. 94, no. 3, pp. 367-374, 1987.

[22] M. Thubrikar, L. P. Bosher, and S. P. Nolan, "The mechanism of opening of the aortic valve," Journal of Thoracic and Cardiovascular Surgery, vol. 77, no. 6, pp. 863-870, 1979.

[23] M. Thubrikar, S. P. Nolan, L. P. Bosher, and J. D. Deck, "The cyclic changes and structure of the base of the aortic valve," American Heart Journal, vol. 99, no. 2, pp. 217-224, 1980.

[24] M. J. Thubrikar, S. P. Nolan, J. Aouad, and J. D. Deck, "Stress sharing between the sinus and leaflets of canine aortic valve," Annals of Thoracic Surgery, vol. 42, no. 4, pp. 434-440, 1986.

[25] G. W. Christie and B. G. Barratt-Boyes, "Age-dependent changes in the radial stretch of human aortic valve leaflets determined by biaxial testing," Annals of Thoracic Surgery, vol. 60, supplement 2, pp. S156-S159, 1995. 
[26] K. T. Weber, Y. Sun, L. C. Katwa, J. P. M. Cleutjens, and G. Zhou, "Connective tissue and repair in the heart. Potential regulatory mechanisms," Annals of the New York Academy of Sciences, vol. 752, pp. 286-299, 1995.

[27] P. J. Schneider and J. D. Deck, "Tissue and cell renewal in the natural aortic valve of rats: an autoradiographic study," Cardiovascular Research, vol. 15, no. 4, pp. 181-189, 1981.

[28] I. E. M. G. Willems, M. G. Havenith, J. F. M. Smits, and M. J. A. P. Daemen, "Structural alterations in heart valves during left ventricular pressure overload in the rat," Laboratory Investigation, vol. 71, no. 1, pp. 127-133, 1994.

[29] M. Chaput, M. D. Handschumacher, F. Tournoux et al., "Mitral leaflet adaptation to ventricular remodeling occurrence and adequacy in patients with functional mitral regurgitation," Circulation, vol. 118, no. 8, pp. 845-852, 2008.

[30] J. P. Dal-Bianco, E. Aikawa, J. Bischoff et al., "Active adaptation of the tethered mitral valve: insights into a compensatory mechanism for functional mitral regurgitation," Circulation, vol. 120, no. 4, pp. 334-342, 2009.

[31] C. A. Simmons, G. R. Grant, E. Manduchi, and P. F. Davies, "Spatial heterogeneity of endothelial phenotypes correlates with side-specific vulnerability to calcification in normal porcine aortic valves," Circulation Research, vol. 96, no. 7, pp. 792-799, 2005.

[32] D. W. Quick, K. S. Kunzelman, J. M. Kneebone, and R. P. Cochran, "Collagen synthesis is upregulated in mitral valves subjected to altered stress," ASAIO Journal, vol. 43, no. 3, pp. 181-186, 1997.

[33] B. F. Stewart, D. Siscovick, B. K. Lind et al., "Clinical factors associated with calcific aortic valve disease," Journal of the American College of Cardiology, vol. 29, no. 3, pp. 630-634, 1997.

[34] E. R. Mohler III, F. Gannon, C. Reynolds, R. Zimmerman, M. G. Keane, and F. S. Kaplan, "Bone formation and inflammation in cardiac valves," Circulation, vol. 103, no. 11, pp. 1522-1528, 2001.

[35] Y. Agmon, B. K. Khandheria, I. Meissner et al., "Aortic valve sclerosis and aortic atherosclerosis: different manifestations of the same disease? Insights from a population-based study," Journal of the American College of Cardiology, vol. 38, no. 3, pp. 827-834, 2001.

[36] A. Boon, E. Cheriex, J. Lodder, and F. Kessels, "Cardiac valve calcification: characteristics of patients with calcification of the mitral annulus or aortic valve," Heart, vol. 78, no. 5, pp. 472-474, 1997.

[37] F. S. Agno, M. Chinali, J. N. Bella et al., "Aortic valve sclerosis is associated with preclinical cardiovascular disease in hypertensive adults: the Hypertension Genetic Epidemiology Network study," Journal of Hypertension, vol. 23, no. 4, pp. 867-873, 2005.

[38] P. M. Taylor, P. Batten, N. J. Brand, P. S. Thomas, and M. H. Yacoub, "The cardiac valve interstitial cell," International Journal of Biochemistry and Cell Biology, vol. 35, no. 2, pp. 113$118,2003$.

[39] A. D. Durbin and A. I. Gotlieb, "Advances towards understanding heart valve response to injury," Cardiovascular Pathology, vol. 11, no. 2, pp. 69-77, 2002.

[40] A. C. Liu, V. R. Joag, and A. I. Gotlieb, "The emerging role of valve interstitial cell phenotypes in regulating heart valve pathobiology," American Journal of Pathology, vol. 171, no. 5, pp. 1407-1418, 2007.

[41] J. T. Butcher and R. M. Nerem, "Valvular endothelial cells regulate the phenotype of interstitial cells in co-culture: effects of steady shear stress," Tissue Engineering, vol. 12, no. 4, pp. 905-915, 2006.

[42] P. Sucosky, M. Padala, A. Elhammali, K. Balachandran, H. Jo, and A. P. Yoganathan, "Design of an ex vivo culture system to investigate the effects of shear stress on cardiovascular tissue," Journal of Biomechanical Engineering, vol. 130, no. 3, Article ID 035001-1, 2008.

[43] G. C. Engelmayr Jr., L. Soletti, S. C. Vigmostad et al., "A novel flex-stretch-flow bioreactor for the study of engineered heart valve tissue mechanobiology," Annals of Biomedical Engineering, vol. 36, no. 5, pp. 700-712, 2008.

[44] Y. Xing, Z. He, J. N. Warnock, S. L. Hilbert, and A. P. Yoganathan, "Effects of constant static pressure on the biological properties of porcine aortic valve leaflets," Annals of Biomedical Engineering, vol. 32, no. 4, pp. 555-562, 2004.

[45] Y. Xing, J. N. Warnock, H. Zhaoming, S. L. Hilbert, and A. P. Yoganathan, "Cyclic pressure affects the biological properties of porcine aortic valve leaflets in a magnitude and frequency dependent manner," Annals of Biomedical Engineering, vol. 32, no. 11, pp. 1461-1470, 2004.

[46] P. Thayer, K. Balachandran, S. Rathan et al., "The effects of combined cyclic stretch and pressure on the aortic valve interstitial cell phenotype interstitial cell phenotype," Annals of Biomedical Engineering, vol. 39, no. 6, pp. 1654-1667, 2011.

[47] J. N. Warnock, S. Konduri, Z. He, and A. P. Yoganathan, "Design of a sterile organ culture system for the ex vivo study of aortic heart valves," Journal of Biomechanical Engineering, vol. 127, no. 5, pp. 857-861, 2005.

[48] J. E. Barzilla, F. E. Acevedo, and K. J. Grande-Allen, "Organ culture as a tool to identify early mechanisms of serotonergic valve disease," Journal of Heart Valve Disease, vol. 19, no. 5, pp. 626-635, 2010.

[49] J. E. Barzilla, A. S. McKenney, A. E. Cowan, C. A. Durst, and K. J. Grande-Allen, "Design and validation of a novel splashing bioreactor system for use in mitral valve organ culture," Annals of Biomedical Engineering, vol. 38, no. 11, pp. 3280-3294, 2010.

[50] Y. Leskinen et al., "Valvular calcification and its relationship to atherosclerosis in chronic kidney disease," Journal of Heart Valve Disease, vol. 18, no. 4, pp. 429-438, 2009.

[51] S. A. Salwen, D. H. Szarowski, J. N. Turner, and R. Bizios, "Three-dimensional changes of the cytoskeleton of vascular endothelial cells exposed to sustained hydrostatic pressure," Medical and Biological Engineering and Computing, vol. 36, no. 4, pp. 520-527, 1998.

[52] S. Kitamoto, G. K. Sukhova, J. Sun et al., "Cathepsin L deficiency reduces diet-induced atherosclerosis in low-density lipoprotein receptor-knockout mice," Circulation, vol. 115, no. 15, pp. 2065-2075, 2007.

[53] G. K. Sukhova, Y. Zhang, J. H. Pan et al., "Deficiency of cathepsin S reduces atherosclerosis in LDL receptor-deficient mice," Journal of Clinical Investigation, vol. 111, no. 6, pp. 897906, 2003.

[54] G. K. Sukhova, G. P. Shi, D. I. Simon, H. A. Chapman, and P. Libby, "Expression of the elastolytic cathepsins S and K in human atheroma and regulation of their production in smooth muscle cells," Journal of Clinical Investigation, vol. 102, no. 3, pp. 576-583, 1998.

[55] J. N. Warnock, S. C. Burgess, A. Shack, and A. P. Yoganathan, "Differential immediate-early gene responses to elevated pressure in porcine aortic valve interstitial cells," Journal of Heart Valve Disease, vol. 15, no. 1, pp. 34-42, 2006.

[56] M. W. Weston and A. P. Yoganathan, "Biosynthetic activity in heart valve leaflets in response to in vitro flow environments," 
Annals of Biomedical Engineering, vol. 29, no. 9, pp. 752-763, 2001.

[57] C. M. Otto, "Calcific aortic stenosis-Time to look more closely at the valve," New England Journal of Medicine, vol. 359, no. 13, pp. 1395-1398, 2008.

[58] C. M. Otto, J. Kuusisto, D. D. Reichenbach, A. M. Gown, and K. D. O'Brien, "Characterization of the early lesion of 'degenerative' valvular aortic stenosis: histological and immunohistochemical studies," Circulation, vol. 90, no. 2, pp. 844-853, 1994.

[59] E. Aikawa, M. Nahrendorf, D. Sosnovik et al., "Multimodality molecular imaging identifies proteolytic and osteogenic activities in early aortic valve disease," Circulation, vol. 115, no. 3, pp. 377-386, 2007.

[60] M. O. Platt, Y. Xing, H. Jo, and A. P. Yoganathan, "Cyclic pressure and shear stress regulate matrix metalloproteinases and cathepsin activity in porcine aortic valves," Journal of Heart Valve Disease, vol. 15, no. 5, pp. 622-629, 2006.

[61] N. M. Rajamannan, D. J. Rickard, A. J. Tajik et al., "Human aortic valve calcification is associated with an osteoblast phenotype," Circulation, vol. 107, no. 17, pp. 2181-2184, 2003.

[62] A. A. Damji, I. Gedeon, M. Tanaka, and W. Lester, "Interstitial cells from the atrial and ventricular sides of the bovine mitral valve respond differently to denuding endocardial injury," In Vitro Cellular and Developmental Biology, vol. 29, no. 1, pp. 41-50, 1993.

[63] K. O’Brien, "Pathogenesis of calcific aortic valve disease: a disease process comes of age (and a good deal more)," Arteriosclerosis, Thrombosis, and Vascular Biology, vol. 26, no. 8, pp. 1721-1728, 2006.

[64] M. J. Levesque, S. Moravec, D. Liepsch, and R. M. Nerem, "Correlation of endothelial cell shape and wall shear stress in a stenosed dog aorta," Arteriosclerosis, vol. 6, no. 2, pp. 220-229, 1986.

[65] T. Borg, I. Banerjee, R. A. Norris, T. A. Baudino, J. T. Butcher, and R. R. Markwald, "Neonatal and adult cardiovascular pathophysiological remodeling and repair: developmental role of periostin," Annals of the New York Academy of Sciences, vol. 1123, pp. 30-40, 2008.

[66] J. Warnock, C. A. Simmons, and J. T. Butcher, "Mechanobiology of the aortic heart valve," Journal of Heart Valve Disease, vol. 17, no. 1, pp. 62-73, 2008.

[67] J. T. Butcher and R. R. Markwald, "Valvulogenesis: the moving target," Philosophical Transactions of the Royal Society B, vol. 362, no. 1484, pp. 1489-1503, 2007.

[68] B. Jian, R. Levy, N. Narula, Q. Y. Li, and E. R. Mohler, "Progression of aortic valve stenosis: TGF- $\beta 1$ is present in calcified aortic valve cusps and promotes aortic valve interstitial cell calcification via apoptosis," Annals of Thoracic Surgery, vol. 75, no. 2, pp. 457-465, 2003.

[69] J. T. Butcher and R. R. Markwald, "The next frontier in cardiovascular developmental biology-An integrated approach to adult disease?" Nature Clinical Practice Cardiovascular Medicine, vol. 4, no. 2, pp. 60-61, 2007.

[70] H. S. Rapoport, R. Levy, J. N. Clark-Greuel et al., "Transforming growth factor- $\beta 1$ mechanisms in aortic valve calcification: increased alkaline phosphatase and related events," Annals of Thoracic Surgery, vol. 83, no. 3, pp. 946-953, 2007.

[71] S. Miriyala, M. C. G. Nieto, D. A. Smith et al., "Bone morphogenic protein-4 induces hypertension in mice: role of noggin, vascular NADPH oxidases, and impaired vasorelaxation," Circulation, vol. 113, no. 24, pp. 2818-2825, 2006.
[72] G. P. Sorescu, J. Hwang, N. L. Boyd et al., "Bone morphogenic protein 4 produced in endothelial cells by oscillatory shear stress stimulates an inflammatory response," Journal of Biological Chemistry, vol. 278, no. 33, pp. 31128-31135, 2003.

[73] P. Sucosky, A. Elhammali, K. Balachandran, H. Jo, and A. P. Yoganathan, "Altered shear stress stimulates upregulation of endothelial VCAM- 1 and ICAM- 1 in a BMP-4- and TGF- $\beta 1$ dependent pathway," Arteriosclerosis, Thrombosis, and Vascular Biology, vol. 29, no. 2, pp. 254-260, 2009.

[74] D. Hoehn, L. Sun, and P. Sucosky, "Role of pathologic shear stress alterations in aortic valve endothelial activation," Cardiovascular Engineering and Technology, vol. 1, no. 2, pp. 165-178, 2010.

[75] D. Lo and I. Vesely, "Biaxial strain analysis of the porcine aortic valve," Annals of Thoracic Surgery, vol. 60, supplement 2, pp. S374-S378, 1995.

[76] J. Liao, C. A. Gamez, S. Elder, S. A. Metzler, J. Chen, and J. N. Warnock, "Vasoactive agents alter the biomechanical properties of aortic heart valve leaflets in a time-dependent manner," Journal of Heart Valve Disease, vol. 19, no. 1, pp. 8696, 2010.

[77] K. E. Smith, S. A. Metzler, and J. Warnock, "Cyclic strain inhibits acute pro-inflammatory gene expression in aortic valve interstitial cells," Biomechanics and Modeling in Mechanobiology, vol. 9, no. 1, pp. 117-125, 2010.

[78] P. Batten, C. H. Ku, P. H. Johnson et al., "Collagen synthesis by mesenchymal stem cells and aortic valve interstitial cells in response to mechanical stretch," Cardiovascular Research, vol. 71, no. 3, pp. 548-556, 2006.

[79] K. Balachandran, P. Sucosky, S. Konduri, H. Jo, and A. P. Yoganathan, "An ex vivo study of the biological properties of porcine aortic valves in response to circumferential cyclic stretch," Annals of Biomedical Engineering, vol. 34, no. 11, pp. 1655-1665, 2006.

[80] P. Sucosky, K. Balachandran, H. Jo, and A. P. Yoganathan, "Elevated cyclic stretch alters matrix remodeling in aortic valve cusps: implications for degenerative aortic valve disease," American Journal of Physiology, vol. 296, no. 3, pp. H756H764, 2009.

[81] R. A. Hopkins, H. D. Lukoff, R. A. Long, W. D. Merryman, M. S. Sacks, and G. C. Engelmayr, "Synergistic effects of cyclic tension and transforming growth factor- $\beta 1$ on the aortic valve myofibroblast," Cardiovascular Pathology, vol. 16, no. 5, pp. 268-276, 2007.

[82] W. D. Merryman, F. Guilak, R. A. Hopkins et al., "Correlation between heart valve interstitial cell stiffness and transvalvular pressure: implications for collagen biosynthesis," American Journal of Physiology, vol. 290, no. 1, pp. H224-H231, 2006.

[83] J. H. Chen, C. Y. Y. Yip, R. Zhao, and C. A. Simmons, "Calcification by valve interstitial cells is regulated by the stiffness of the extracellular matrix," Arteriosclerosis, Thrombosis, and Vascular Biology, vol. 29, no. 6, pp. 936-942, 2009.

[84] C. Choqueux, D. Detaint, M. P. Jacob et al., "Extracellular matrix remodelling in human aortic valve disease: the role of matrix metalloproteinases and their tissue inhibitors," European Heart Journal, vol. 26, no. 13, pp. 1333-1341, 2005.

[85] F. T. Bosman and I. Stamenkovic, "Functional structure and composition of the extracellular matrix," Journal of Pathology, vol. 200, no. 4, pp. 423-428, 2003.

[86] C. M. Dollery, A. M. Henney, and J. R. Mcewan, "Matrix met-alloproteinases and cardiovascular disease," Circulation Research, vol. 77, no. 5, pp. 863-868, 1995. 
[87] J. R. Stone, E. Rabkin, Y. Fukumoto, P. Libby, M. Aikawa, and F. J. Schoen, "Activated interstitial myofibroblasts express catabolic enzymes and mediate matrix remodeling in myxomatous heart valves," Circulation, vol. 104, no. 21, pp. 25252532, 2001.

[88] P. Sucosky, K. Balachandran, H. Jo, and A. P. Yoganathan, "Elevated cyclic stretch induces aortic valve calcification in a bone morphogenic protein-dependent manner," American Journal of Pathology, vol. 177, no. 1, pp. 49-57, 2010.

[89] Z. Ferdous, H. Jo, and R. M. Nerem, "Differences in valvular and vascular cell responses to strain in osteogenic media," Biomaterials, vol. 32, no. 11, pp. 2885-2893, 2011.

[90] Y. Xing, S. Konduri, J. Warnock, Z. He, and A. P. Yoganathan, "Normal physiological conditions maintain the biological characteristics of porcine aortic heart valves: an ex vivo organ culture study," Annals of Biomedical Engineering, vol. 33, no. 9, pp. 1158-1166, 2005.

[91] B. Wilkins, T. C. Flanagan, A. Black, T. J. Smith, A. Pandit, and S. Jockenhoevel, "A collagen-glycosaminoglycan coculture model for heart valve tissue engineering applications," Biomaterials, vol. 27, no. 10, pp. 2233-2246, 2006.

[92] I. El-Hamamsy, M. H. Yacoub, and A. H. Chester, "Neuronal regulation of aortic valve cusps," Current Vascular Pharmacology, vol. 7, no. 1, pp. 40-46, 2009.

[93] C. Moraes, J. H. Chen, Y. Sun, and C. A. Simmons, "Microfabricated arrays for high-throughput screening of cellular response to cyclic substrate deformation," Lab on a Chip, vol. 10, no. 2, pp. 227-234, 2010.

[94] M. Weiler, C. Hwai Yap, K. Balachandran, M. Padala, and A. P. Yoganathan, "Regional analysis of dynamic deformation characteristics of native aortic valve leaflets," Journal of Biomechanics, vol. 44, no. 8, pp. 1459-1465, 2011. 


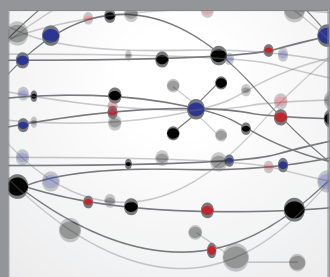

The Scientific World Journal
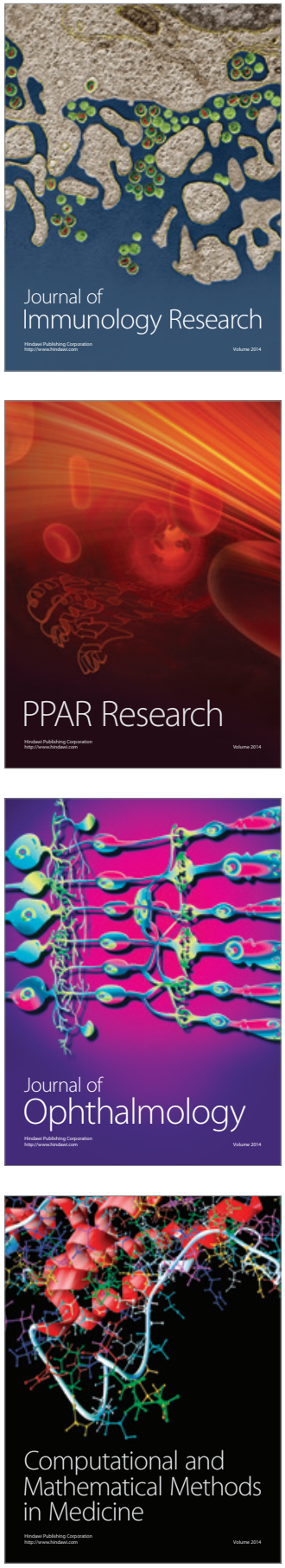

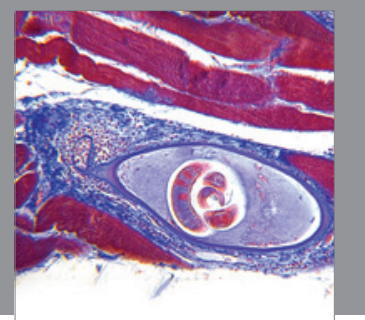

Gastroenterology

Research and Practice
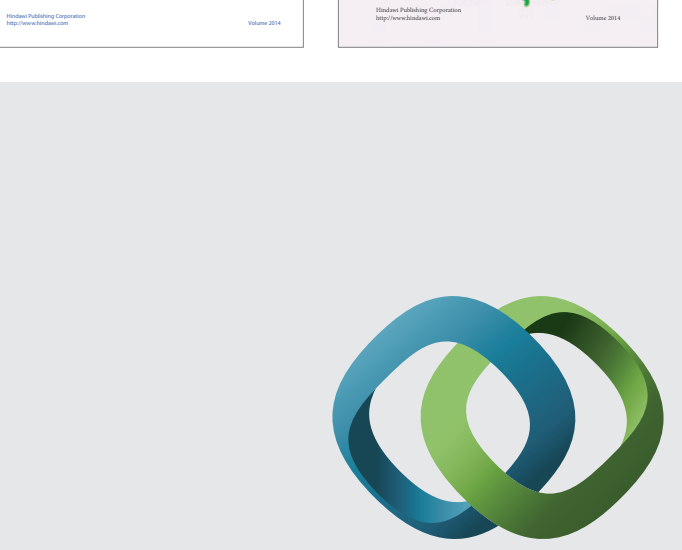

\section{Hindawi}

Submit your manuscripts at

http://www.hindawi.com
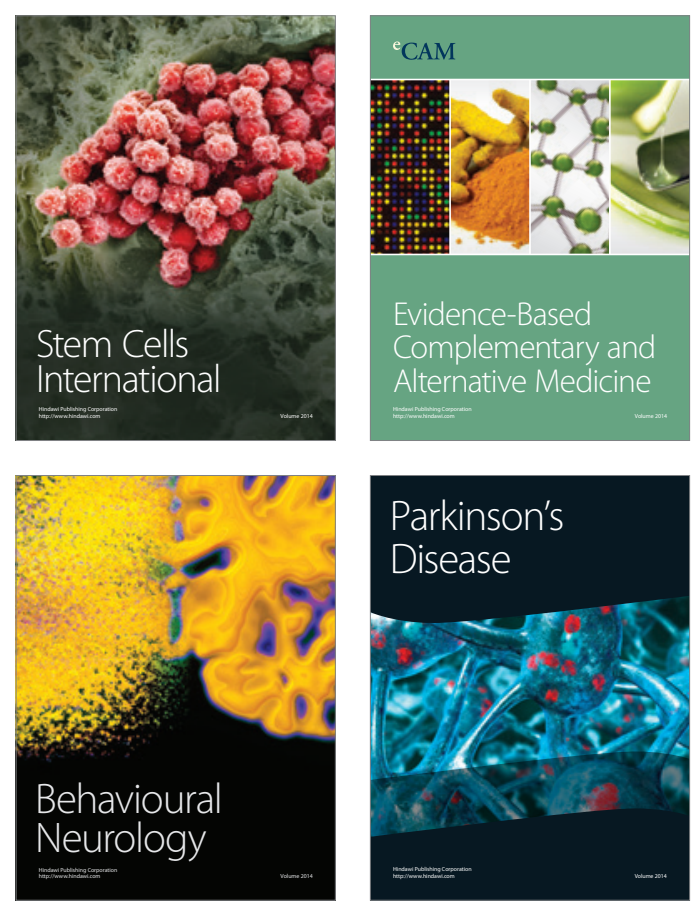

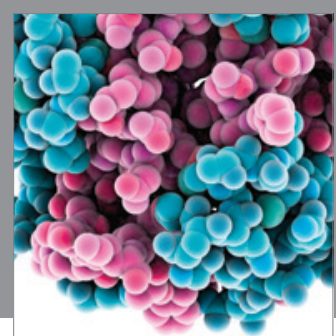

Journal of
Diabetes Research

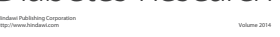

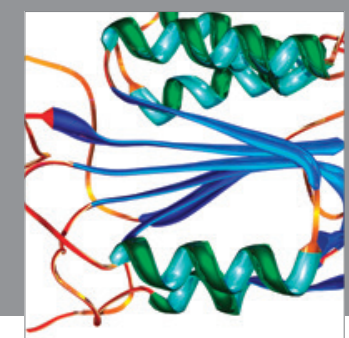

Disease Markers
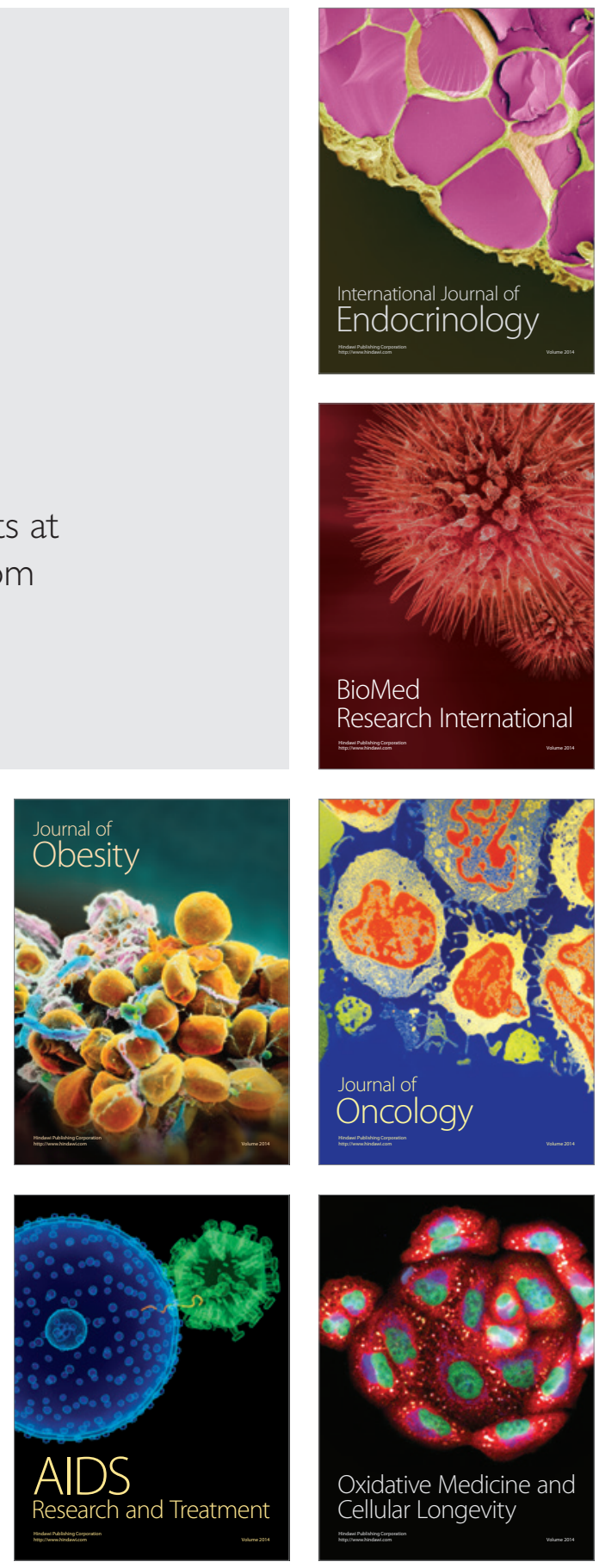